\title{
LA SECT. LONCHOCARPUS DEL GÉNERO LONCHOCARPUS (LEGUMINOSAE, PAPILIONOIDEAE, MILLETTIEAE): NUEVAS ESPECIES Y SUBESPECIE PARA MÉXICO Y MESOAMÉRICA
}

\author{
Mario Sousa S. \\ Universidad Nacional Autónoma de México, Instituto de Biología, \\ Apdo. postal 70-367, 04510 México, D.F., México.sousa@servidor.unam.mx
}

\section{RESUMEN}

Se describen e ilustran nuevos taxones para el género Lonchocarpus (Leguminosae, Papilionoideae, Millettieae) para México y Mesoamérica. De las 19 especies reconocidas en esta sección, ocho son nuevas para la ciencia: L. brenesii, L. isthmensis, L. latimarginatus, L. michoacanicus, L. pedunculatus, L. plicatus, L. subsessilifolius y $L$. wendtii, y una nueva subespecie de L. brenesii subsp. vulcanicola. Al aumentarse significativamente el número de sus componentes reconocidos se caracteriza de nuevo a la sección Lonchocarpus y se contrastan las diferencias de sus representantes con una clave dicotómica.

Palabras clave: Leguminosae, Lonchocarpus, Mesoamérica, México, sect. Lonchocarpus.

\begin{abstract}
New taxa of the Lonchocarpus genus from Mexico and Mesoamerica (Leguminosae, Papilionoideae, Millettieae) are described and illustrated. Of the 19 recognized species, eight species: L. brenesii, L. isthmensis, L. latimarginatus, L. michoacanicus, L. pedunculatus, $L$. plicatus, $L$. subsessilifolius and $L$. wendtii, and a new subspecies of $L$. brenesii, subsp. vulcanicola, are new to science. The Lonchocarpus section is once again characterized with this significant increase in the number of its known species. Mesoamerican species and subspecies of the Lonchocarpus section show contrasting differences in the dichotomous key.
\end{abstract}

Key words: Leguminosae, Lonchocarpus, Mesoamerica, Mexico, sect. Lonchocarpus. 
El género Lonchocarpus Kunth (Leguminosae, Papilionoideae, Millettieae) incluye alrededor de 160 especies de los trópicos de América y una en la costa occidental de África ecuatorial. La sect. Lonchocarpus consta de alrededor de 47 especies, y está bien representada en Mesoamérica y Sudamérica con 20 en cada región. De estas sólo una es exclusiva a México y nueve están en el área fitogeográfica mesoamericana de México o se extienden a Mesoamérica; siete son exclusivas a Mesoamérica y dos se comparten con Sudamérica; en las Antillas se cuenta con seis y una en África.

Con este trabajo al aumentarse grandemente el número de especies dentro de la sect. Lonchocarpus, su caracterización requiere una actualización a las descripciones dadas por Sousa $(2005,2009,2010)$. Además en Sousa (2009) se incluyó en la sect. Standleyi M. Sousa a dos especies que ahora se pasan a la sect. Lonchocarpus, se trata de L. chiangii M. Sousa y L. oliganthus F.J. Hermann. Ambas presentan bractéolas pequeñas (0.7-1.1 mm de largo), que antes considerábamos exclusivas de la sect. Standleyi, pero ahora tomando en cuenta una nueva evaluación y adición de caracteres, éstas deben ser incluidas como parte de la variación en la sect. Lonchocarpus. Las mencionadas especies pertenecen a un grupo situado alrededor de $L$. nitidus (Vogel) Benth., planta del sur de Sudamérica, que en nuestra área geográfica está representado por L. hondurensis Benth. y L. michoacanicus M. Sousa. Todas ellas comparten características como el tamaño de las bractéolas, las hojas glabras a casi glabras, epunteadas, y frutos glabrescentes de 1.3-2.8 cm de ancho.

\section{Lonchocarpus Kunth sect. Lonchocarpus}

Nov. Gen. Sp. (folio ed.) 6: 300. 1824. Especie tipo: Lonchocarpus sericeus (Poir.) Kunth ex DC.

Árboles, arbolitos y arbustos; corteza interior con exudado frecuentemente abundante de resina rojiza al corte, en ocasiones poca o ausente; hojas con disposición dística en las ramas; folíolos generalmente con el ápice acuminado; flores con bractéolas cercanas y adpresas a la base del cáliz; bracteólas pequeñas a grandes, las grandes generalmente oblatas y cubriendo hasta un 1/4 la base del cáliz; cáliz truncado a casi truncado; lámina del estandarte adaxialmente de moderada a densamente serícea, abaxialmente canescente pelosa en la parte central de la base hasta el tercio inferior de la lámina, o bien la pelosidad confinada a la base central en la línea de unión con la uña, ocasionalmente sobre la uña, aurículas y callos presentes en 
la base; mecanismo floral fuertemente explosivo; legumbres indehiscentes, pero en ocasiones se fraccionan a manera de lomento en unidades monospermas, el margen vexilar frecuentemente ensanchado, en ocasiones aquillado (Sousa, 2010) como en el complejo Lonchocarpus cruentus Lundell; semillas de chicas a grandes, las chicas de colores claros, las grandes frecuentemente de colores oscuros a negruzcos; plántulas epígeas, eófilos opuestos y simples.

Lonchocarpus brenesii M. Sousa, sp. nov. Tipo: Costa Rica, Alajuela, cerca del Río Poás, Alajuela. Grecia, altitud 700-800 m; 11 diciembre 1932. A.M. Brenes 21 (holotipo: F; isotipo: CR). Fig. 1.

Lonchocarpo macrophyllo Kunth affinis, a quo foliis plerumque 7-9(-11)-foliolatis, (vs.(7-)9-11(-13)), floribus congestis (vs. moderate dispersis); bracteolis minoribus 1.2-1.5 mm longis (vs. 1.5-1.8 mm); legumine usque ad $16 \mathrm{~cm}$ longo (vs. 12.5 $\mathrm{cm}$ ), valvis chartaceis (vs. coriaceis vel sublignosis), margine vexillari 2.3-3.3 mm crasso, 3-nervi (vs. (3-)4-5.5 mm, complanato vel sulcato) differt.

Árboles 7-22(-35) m de alto; corteza interior con fluido resinoso al corte; ramas jóvenes moderadamente canescente seríceas, pronto glabras. Hojas con estípulas c. $2 \mathrm{~mm}$ de largo, ovadas, caducas; pecíolo $2.5-5 \mathrm{~cm}$ de largo, canaliculado; hojas 7-9(-11)-folioladas; folíolos (3.5-)6-8.5(-9.5) cm de largo, (1.4-)2.4-3.7(-5) $\mathrm{cm}$ de ancho, elipticos a angostamente elípticos, rara vez ovados, la base breve a largamente cuneada, el ápice acuminado a largamente acuminado, brillantes, glabros, verdosos en el haz, opacos y muy esparcidamente pardo-amarillento seríceos, más moderadamente sobre las nervaduras en el envés, cartáceos a subcoriáceos, epunteados; nervadura primaria y secundarias ligeramente realzadas en el envés, las laterales 7-9 pares. Inflorescencias 8-21 cm de largo, simples, axilares, erectas, congestifloras; pedunculadas, los pedúnculos $3.5-5 \mathrm{~cm}$ de largo, floración tardía; pedúnculos florales 2-2.5 mm de largo, robustos; pedicelos 2-5 mm de largo, esbeltos; bractéolas 1.2-1.5 mm de largo, 1.1-1.2 $\mathrm{mm}$ de ancho, ligulares, obovadas, opuestas, cercanas al cáliz y adpresas a él, caducas. Flores 11-14 mm de largo; cáliz 3-4 mm de largo, truncado, epunteado, densamente pardo-amarillento seríceo a tomentoso; corola lila, rosada a morada, epunteada, la lámina del estandarte 11-14 mm de ancho, suborbicular, moderadamente canescente serícea adaxialmente, en la base-centro canescente abaxialmente; ovario 9-10-ovulado. Legumbre 6-8 cm de largo cuando con una semilla, 8.5-12.5 cm de largo cuando con dos a tres semillas, 2-2.1 cm de ancho, elíptica, algo falcada cuando con una semilla, oblonga a linear cuando son 
más, indehiscente, aplanada, las valvas con poco pronunciados abombamientos a la altura de las semillas, con nervaduras escasas e imperceptibles, estipitada en la base, redondeada y rostrada en el ápice, cartácea, moderada a esparcidamente pardo-amarillento serícea, el margen vexilar 2-3.3 mm de grueso, 3-nervado, se presenta una fisura a todo lo largo, el margen carinal aquillado; semillas 1-3, 10-12.3 mm de largo, 6-7 $\mathrm{mm}$ de ancho, casi negras.

Etimología. La especie se dedica a Alberto M. Brenes (1870-1948), botánico costarricense, cuyas colectas fueron más de 20,000 números, siendo él uno de los primeros en herborizar a esta especie.

Lonchocarpus brenesii M. Sousa subsp. brenesii.

Árboles hasta $35 \mathrm{~m}$ de alto. Hojas con folíolos (3.5-)6-8.5(-9.5) cm de largo, (1.4-)2.4-3.7(-5) cm de ancho, elípticos a angostamente elípticos, base largamente cuneada, ápice acuminado a largamente acuminado, verdosos; ovario 9-10-ovulado. Legumbre hasta $12.5 \mathrm{~cm}$ de largo, 2-2.1 cm de ancho, elíptica a oblonga, las valvas con las nervaduras escasas e imperceptibles.

Distribución, hábitat y fenología: subespecie distribuida de Honduras a Costa Rica en áreas montañosas como elemento de bosques húmedos, en cañadas con presencia de ríos. En altitudes de 500-900 $\mathrm{m}$. La floración se presenta de principios de agosto a finales de septiembre; la fructificación se inicia a principios de octubre con frutos maduros a mediados de diciembre.

Material adicional examinado: HONDURAS: Olancho: cañón del río del Monumento Natural El Boquerón, ca. $28 \mathrm{~km}$ al NE de Juticalpa, J. L. Linares y J. López 1940 (EAP, MEXU).

NICARAGUA: Boaco: camino a Mombachito a los lados de la Quebrada Río Grande, al NE de Cerro Mombachito, $1^{\circ} 25^{\prime} \mathrm{N}, 85^{\circ} 32^{\prime}$ O, P.P. Moreno 3222 (MEXU); Lapita, camino a Malacatoya, $3.5 \mathrm{~km}$ al E, municipio de San José de los Remates, $12^{\circ} 35^{\prime} \mathrm{N}, 85^{\circ} 44^{\prime} \mathrm{O}$, Moreno 24883 (MEXU, MO).

Chontales: $3 \mathrm{~km}$ al N de Cuapa, D. Neill 2543 (MO).

Matagalpa: La Estancia "El Comelar", carr. Matagalpa - Waslala, NE del Cerro Peñas Blancas, A. Grijalva y P. P. Moreno 1038 (MEXU, MO); carr. al Tuma, $0.5 \mathrm{~km}$ antes de la entrada a "La Cumplida", M. Guzmán et al. 736 (MEXU, MO); $1.5 \mathrm{~km}$ al NE de Los Ángeles, sobre la carr. Matagalpa-Siuna, $13^{\circ} 12^{\prime} \mathrm{N}, 85^{\circ} 41^{\prime} \mathrm{O}, P$. 
Sousa S.: La sección Lonchocarpus, nuevas especies y subespecie para México y Mesoamérica

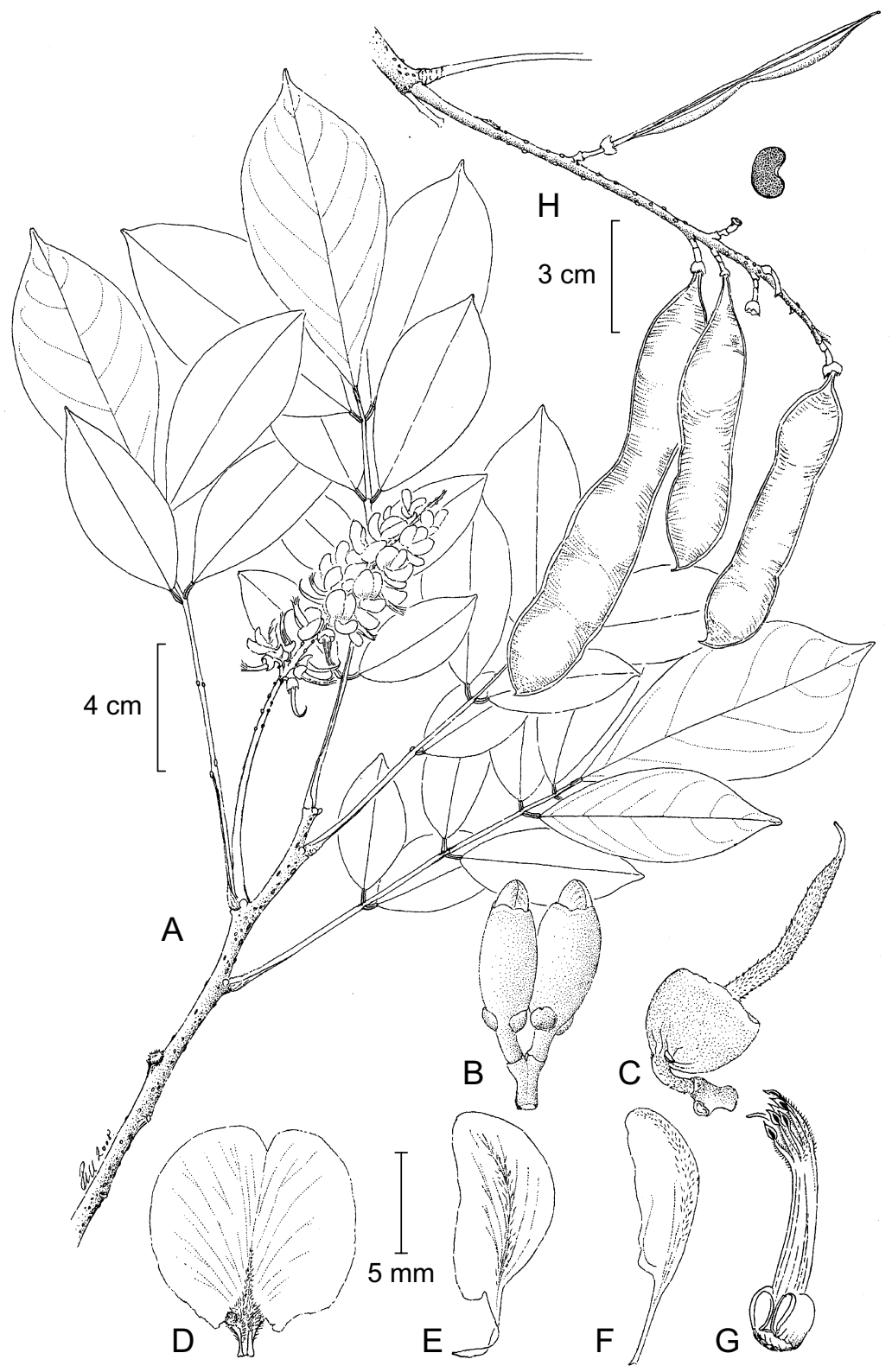

Fig. 1. Lonchocarpus brenesii M. Sousa subsp. brenesii. A. rama con hojas e inflorescencias; B. botones florales, mostrando unidad biflora, pedúnculo floral, pedicelos y bractéolas; C. cáliz y gineceo; D. cara abaxial del estandarte; E. ala; F. pétalo de la quilla; G. tubo estaminal; H. infrutescencia, frutos y semilla. Rama con hojas, inflorescencia y flores tomadas de P. P. Moreno 17173 (MEXU); infrutescencias, frutos y semilla tomados del holotipo: A. Brenes 21 (F). 
P. Moreno 17173 (MEXU, MO); Valley of Río Yasica, $20 \mathrm{~km}$ E of Matagalpa, along Río Yasica, at confluence of Río La Cumplida, D. Neill 2375 (MEXU, MO).

COSTA RICA: Alajuela: Carrillos de Poás, A. M. Brenes 19792, 19793, 19794, 19795, 19796, 192846 (?) (CR).

San José: Finca Morera, $20 \mathrm{~km}$ antes de Vara Blanca, Virgen del Socorro Río Sarapiqui - Cariblanco, I. A. Chacón y G. Herrera 1180 (MEXU, MO); 8 km N of Naranjo, Interamerican Highway, W. Haber 414 (MEXU, MO).

Lonchocarpus brenesii subsp. vulcanicola M. Sousa, subsp. nov. Tipo: México, Chiapas, volcán Tacaná, Unión, 17-23 marzo 1939, E. Matuda 2798 (holotipo; MEXU; isotipos: EAP, MICH, US). Fig. 2.

Nombre común: polvo de queso (El Salvador).

A subspecie typica statura minore ad $22 \mathrm{~m}$ (vs. ad $35 \mathrm{~m}$ ), foliolis (3-)6-11 cm longis, (1.4-)2.3-4.7(-6) cm latis, ellipticis vel late ellipticis (vs. (3.5-)6-8.5(-9.5) cm longis, (1.4-)2.4-3.7(-5) cm latis, ellipticis vel anguste ellipticis); foliolis basi breviter cuneata (vs. longe cuneata), apice acuminato vel obtuso (vs. acuminato vel longe acuminato), plerumque atratis (vs. viridescentibus), ovario 6-9 ovulato (vs. 9-10ovulato), legumine $1.5-1.8 \mathrm{~cm}$ lato (vs. $2-2.1 \mathrm{~cm}$ lato), falcato, valvis nervis numerosis, prominentibus (vs. valvis nervis parcis, non perceptilibus) differt.

Árboles hasta $22 \mathrm{~m}$ de alto. Hojas con folíolos (3-)6-11 cm de largo, (1.4-)2.3$4.7(-6) \mathrm{cm}$ de ancho, elípticos a anchamente elípticos, base brevemente cuneada a redondeada, ápice acuminado a obtuso, frecuentemente negruzcos; ovario 6-9-ovulado. Legumbre, $1.5-1.8 \mathrm{~cm}$ de ancho, falcada, las valvas con las nervaduras numerosas y realzadas.

Distribución, hábitat y fenología: subespecie extendida de México a El Salvador, generalmente habita en orografía volcánica con vegetación de bosques caducifolios con Liquidambar. En altitudes elevadas entre 1500 a $2400 \mathrm{~m}$. La floración es de mediados de marzo a principios de julio, con una adicional fuera del período a finales de octubre, la fructificación se inicia a finales de junio, con frutos maduros a mediados de noviembre.

Etimología. El nombre de la subespecie hace énfasis en su preferencia al prosperar sobre volcanes. 
Sousa S.: La sección Lonchocarpus, nuevas especies y subespecie para México y Mesoamérica

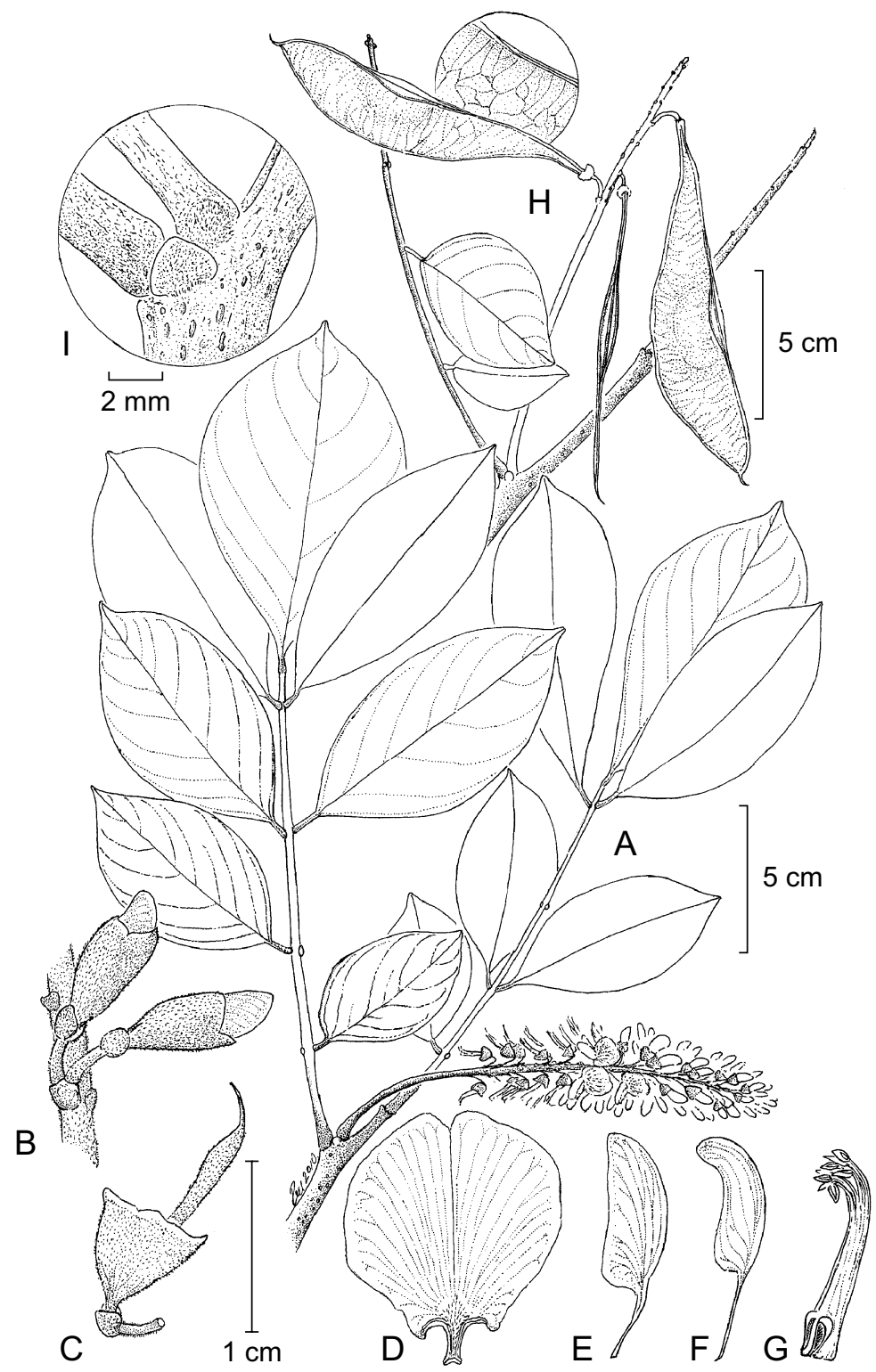

Fig. 2. Lonchocarpus brenesii M. Sousa subsp. vulcanicola M. Sousa. A. rama con hojas e inflorescencia; B. unidad biflora con pedúnculo floral, pedicelos, bractéolas y botones florales; C. cáliz y gineceo; D. cara abaxial del estandarte; E. ala; F. pétalo de la quilla; G. tubo estaminal; H. rama con hoja e infrutescencia, mostrando cara valvar, margen vexilar y detalle de la nervación valvar; I. estípula. Rama con hojas, inflorescencia, flores y sus partes tomados de Molina R. y Molina 12291 (NY); rama con hoja e infrutescencia tomados de Reyna de Aguilar 923 (EAP); estípula tomada de Carballo 398 (MEXU). 
Material adicional examinado: GUATEMALA: Alta Verapaz: NO de Tactic, $6 \mathrm{~km}$ a Estor, A. Molina R. y A. R. Molina 12291 (EAP, NY, US).

Suchitepequez: Finca Moca, A. F. Skutch 1562 (NY).

HONDURAS: Ocotepeque: Cruz Alta, $5 \mathrm{~km}$ al N de Belén, Gualcho, Cordi-

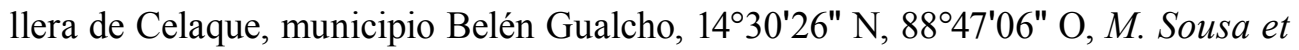
al. 13337 (EAP, MEXU, MO).

EL SALVADOR: Metapan: El Trifinio, Parque Nacional Montecristo, a 22 $\mathrm{km}$ al NE de Metapan, M. L. Reyna 923 (EAP), 1283 (MO).

Santa Ana: Parque Nacional Montecristo, calle al Trifinio. $14^{\circ} 24^{\prime} \mathrm{N}, 89^{\circ} 21^{\prime}$ O, R. A. Caballero 398 (MEXU).

Especie cercana a Lonchocarpus macrophyllus Kunth, pero difiere de ella por sus hojas con relativamente menos folíolos; las flores congestas en las inflorescencias en vez de moderadamente espaciadas; las bractéolas aplanadas y adpresas al cáliz en toda su longitud, y más pequeñas (1.2-1.5 $\mathrm{mm}$ de largo) en vez de adpresas al cáliz sólo en la base y patentes en el ápice, ligeramente más grandes 1.5-2 mm de largo; la legumbre con las valvas cartáceas (vs. coriáceas a subleñosas), el margen vexilar 2-3.3 mm de grueso, 3-nervado (vs. 4-5.5 mm de grueso, aplanado a sulcado).

La subespecie L. brenesii subsp. vulcanicola difiere de la típica por sus foliolos más largos y anchos, elípticos a anchamente elípticos, en vez de más chicos y elípticos a angostamente elípticos; en los foliolos la base es brevemente cuneada, con el ápice acuminado a obtuso y al secar se tornan negruzcos; en la otra subespecie los folíolos en la base son largamente cuneados y el ápice acuminado a largamente acuminado y secan de color verde; el ovario con 6-9 óvulos y la otra subespecie con 9-10 óvulos. Las legumbres con las valvas con nervaduras numerosas y realzadas, mientras que en L. brenesii ssp. brenesii son escasas e imperceptibles.

Lonchocarpus isthmensis M. Sousa, sp. nov. Tipo: México, Oaxaca, km 15 carr. Tapanatepec a Tuxtla Gutiérrez, límite del estado de Oaxaca, 26 febrero 1981, $R$. Cedillo Trigos 582 (holotipo: MEXU; isotipos: ENCB, MEXU, NY). Fig. 3.

Nombre común: guajillo (en Oaxaca).

A Lonchoparpo lineato Pittier similis a quo, habito omnino denudato (vs. sempervirenti vel parumper denudato), foliis plerumque maiore numero foliolorum (5-)7-9 (vs. 5(-7)), foliolis minoribus (2-)3.5-5(6.5) cm longis, 1.5-2(-2.6) cm latis (vs. (3.5-)5$8(-11.5) \mathrm{cm}$ longis, (1-7-)3-4(-7) cm latis), foliolo terminali lateralia aequanti vel leviter 
Sousa S.: La sección Lonchocarpus, nuevas especies y subespecie para México y Mesoamérica

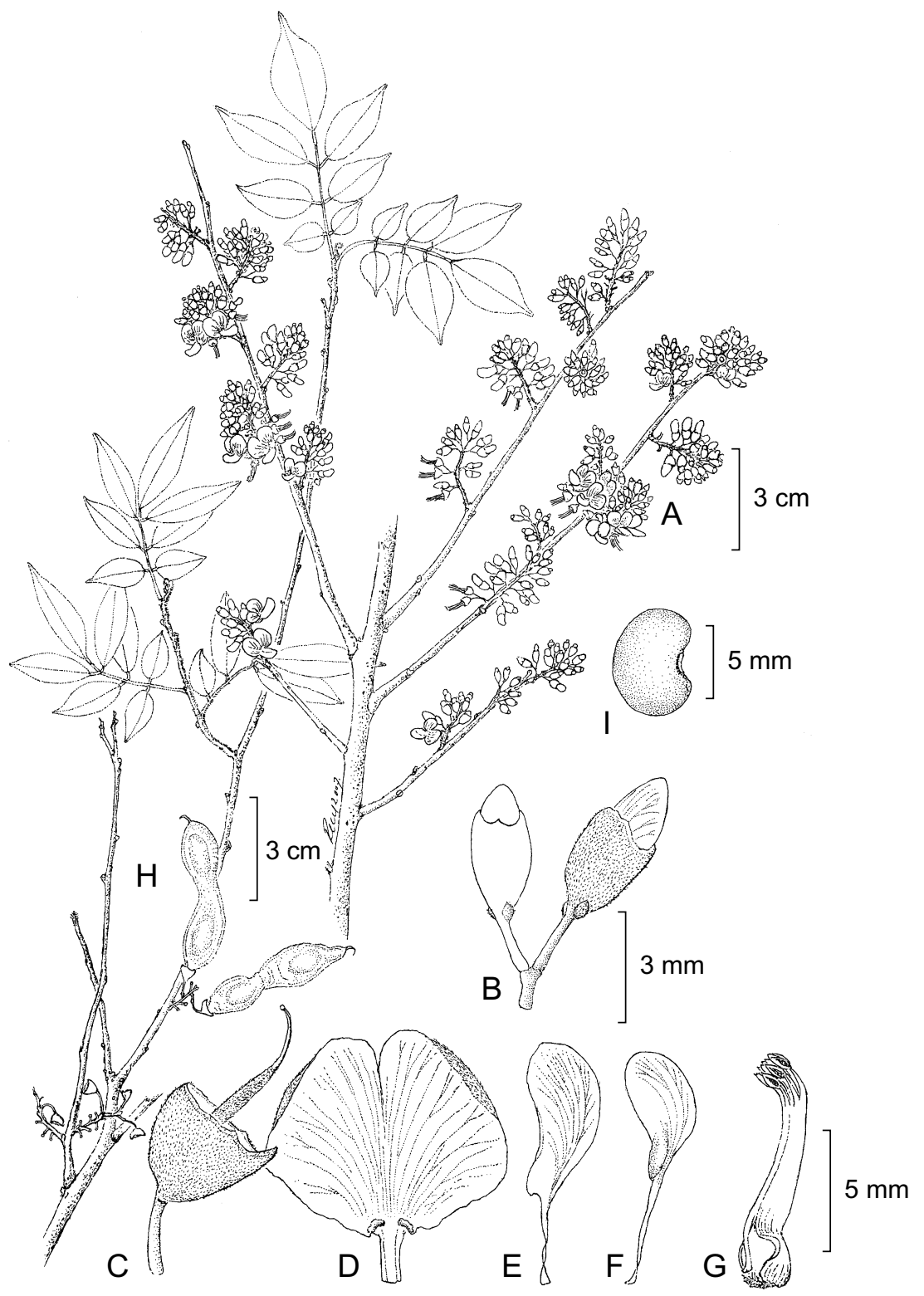

Fig. 3. Lonchocarpus isthmensis M. Sousa. A. ramas una con inflorescencias precoces y otra con hojas ya desarrolladas; B. unidad biflora mostrando pedúnculo floral, pedicelos, bractéolas y botones florales; C. cáliz y gineceo; D. cara abaxial del estandarte; E. ala; F. pétalo de la quilla; G. tubo estaminal; H. infrutescencia y frutos; I. semilla. Ramas con inflorescencia y hojas, botones florales y flor tomadas del holotipo: R. Cedillo T. 582 (MEXU); infrutescencias, frutos y semilla tomados de D. Breedlove 24690 (MEXU). 
superanti (vs. plerumque multum maiore), inflorescentiis ovoideis (vs. cylindricis); florescentia praecoci vel serotina (vs. serotina); pedunculo florali 2-4 mm longo, gracili (vs. 0.5-1.2 mm longo, robusto), floribus 11-14 mm longis (vs. 9-10 mm) differt.

Arbolitos a árboles 4-15 m de alto, caducifolios; corteza interior sin fluido resinoso al corte; ramas densamente pardo-amarillento tomentulosas, posteriormente glabrescentes. Hojas con estípulas 1.4-1.6 mm de largo, ligulares a triangulares, caducas; pecíolo 0.8-2 cm de largo, canaliculado; hojas (5-)7-9-folioladas; folíolos (2-)3.5$5(-6.5) \mathrm{cm}$ de largo, 1.5-2(-2.6) $\mathrm{cm}$ de ancho, el folíolo terminal con frecuencia ligeramente más grande que los laterales a tan grande como ellos, elípticos y ovados, la base cuneada o en ocasiones redondeada, algo asimétrica, el ápice acuminado a casi caudado, cartáceos, epunteados, ligeramente discoloros, sin brillo, esparcidamente canescente seríceos, más densamente sobre las nervaduras, a glabrescentes sobre el haz, moderada a esparcidamente sobre el envés, nervadura primaria y secundarias ligeramente impresas en el envés, nervaduras laterales 4-6 pares. Inflorescencias 2-4.5 cm de largo, simples, erectas, ovoideas, casi sésiles; flores congestas, floración generalmente precoz a tardía; pedúnculos florales 2-4 mm de largo, esbeltos; pedicelos 4-6 mm de largo; bractéolas 0.8-1 mm de largo, oblongas, lanceoladas, opuestas, cercanas y adpresas al cáliz a patentes. Botones elipsoidales. Flores 11-14 mm de largo; cáliz 4-5 mm de largo, cortamente dentado, los dientes triangulares, agudos, el carinal hasta $1.5 \mathrm{~mm}$, ciatiforme, epunteado, moderada a esparcidamente canescente seríceo sobre un fondo guinda oscuro; corola morada, escarlata o rosada, epunteada, estandarte reflexo, la lámina 9-11 $\mathrm{mm}$ de ancho, oblata, moderadamente canescente serícea adaxialmente, en la base-centro esparcidamente canescente pelosa a glabra abaxialmente; ovario 7-ovulado. Legumbre 3-3.5 $\mathrm{cm}$ de largo cuando con una semilla, 4-5.5 cm de largo cuando con dos a tres, 6-7.2 cm de largo cuando con cuatro a cinco, 0.9-1.4 cm de ancho, oblanceolada, oblongo-linear, indehiscente, casi sésil en la base, obtusa y rostrada en el ápice, lateralmente compresa, recta, en ocasiones ligeramente constricta, membranácea a cartácea, esparcida, moderada a más a menudo densamente canescente tomentulosa a velutina, el margen vexilar y el carinal aquillados; semillas 1-5, 6.7-8.5 $\mathrm{mm}$ de largo, 5-6.3 $\mathrm{mm}$ de ancho, ca. de $2.8 \mathrm{~mm}$ de grueso, color castaño.

Distribución, hábitat, fenología: Especie presente en las estribaciones de la Sierra Madre del Sur y Planicie Costera del Pacífico en Oaxaca, en selvas medianas subcaducifolias y bosques mesófilos, y en el Istmo de Tehuantepec en Oaxaca y área colindante de la Depresión Central de Chiapas, en selvas bajas caducifolias con do- 
minancia de Bursera, vega de ríos y ecotonías de selvas bajas caducifolias con bosques de Pinus-Quercus. En altitudes de 100 a 1400 m. La floración de esta especie que habita en las selvas caducifolias abarca de finales de febrero a finales de mayo, pero su pico es de abril a mediados de mayo; en selvas subperennifolias y bosques mesófilos comprende de finales de octubre a inicios de enero.

Etimología. La especie se encuentra, en gran parte, distribuida en el Istmo de Tehuantepec y el epíteto específico lo resalta.

Material adicional examinado (poblaciones de la Sierra Madre del Sur y Planicie Costera del Pacífico): MÉXICO: Oaxaca: DISTRITO POCHUTLA: sobre el camino a la Finca El Faro, $11 \mathrm{~km}$ al N de Xadane, Municipio de San Miguel del Puerto, $16^{\circ} 00^{\prime} \mathrm{N}, 96^{\circ} 04^{\prime} \mathrm{O}$, A. Campos V. et al. 5109 (MEXU); Oreja de León, municipio San Miguel del Puerto, J. Pascual 746, 1303 (MEXU); camino a la Constancia, camino a Santa Clara, municipio San Miguel del Puerto, J. Pascual 1671 (MEXU); Cerro Huatulco, ca. 3 km N de Santa María Huatulco, 1551'25" N, 96²0'50" O, C. A. Pendry et al. 808 (MEXU); a 5 km N Santa María Xadani, camino a Finca Montecarlo, municipio San Miguel del Puerto 1558'39 N, 96 05'09" O, S. H. Salas M. et al. 3518 (MEXU); Finca Montecarlo, municipio San Miguel del Puerto, S. H. Salas M. et al. 4378 (MEXU); $500 \mathrm{~m}$ al S de la finca el Mamey, municipio San Miguel del Puerto, $15^{\circ} 58^{\prime} 38^{\prime \prime}$ N, 96 $05^{\circ} 08^{\prime \prime}$ O, A. Saynes V. et al. 2835 (MEXU); a $500 \mathrm{~m}$ al O del rancho San Agustín, camino al cerro La Campana, municipio San Miguel del Puerto, 1559'34" N, 9606'33" O, A. Saynes V. et al. 2848 (MEXU); arroyo Arena, Santa María Huatulco, J. Vásquez H. 195 (MEXU).

Material adicional examinado (poblaciones del Istmo de Tehuantepec y Depresión Central de Chiapas): MÉXICO: Oaxaca: DISTRITO JUCHITÁN: on the road $\mathrm{N}$ from La Ventosa towards Matías Romero, about $10 \mathrm{~km} \mathrm{~N}$ of La Ventosa $16^{\circ} 37^{\prime} \mathrm{N}, 9^{\circ} 57^{\prime}$ O, C. E. Hughes 1302 (MEXU, NY); faldas del Cerro Timbón, Cieneguilla, municipio Santa María Petapa, 9458'01" N, 16²4'49" O, G. Juárez García et al. 3208 (MEXU); Nizanda, T. MacDougall s.n. (F, NY); Mazahuete, a $15.8 \mathrm{~km}$ NE La Ventosa, municipio Ixtlatepec, M. Sousa S. 3695 (F, MEXU, MICH, MO, US); hacia el paraje "Agua Tibia", a $500 \mathrm{~m}$ al $\mathrm{N}$ de Nizanda, municipio Asunción Ixtlatepec, 160'02" N, 9500'35" O, E. Pérez García y B. Reyes R. 1022, 2322, 2328 (MEXU); $31 \mathrm{~km}$ N de Juchitán, carr. Matías Romero, P. Tenorio L. et al. 3525 (MEXU); $5 \mathrm{~km}$ E de Mazahua, hacia El Zapote, $13 \mathrm{~km}$ al NE La Ventosa, municipio Ixtaltepec, R. Torres C. et al. 11952 (MEXU). 
Chiapas: $6 \mathrm{~km} \mathrm{~N}$ of Arriaga, municipio Arriaga, D. E. Breedlove 24424 (DS); 5-7 km NW of Rizo de Oro, along a logging road to cerro Baúl and Colonia Figueroa, municipio Cintalapa, D. E. Breedlove 24690 (ENCB, MEXU, MO, NY); Pijijiapan, E. Hernández X. 257 (MEXU); W of Rizo de Oro, T. MacDougall s.n. (MEXU); $2.9 \mathrm{~km}$ al NE de la Colonia Ramón E. Balboa, o $8.9 \mathrm{~km}$ NE de Rizo de Oro, hacia Cerro Baúl, R. Torres C. y J. Martínez 4821 (MEXU); a 9 km al NO de Rizo de Oro, hacia Rodolfo Figueroa, municipio Cintalapa, R. Torres C. et al. 5396 (MEXU); Rancho Alianza, a $9 \mathrm{~km}$ al $\mathrm{N}$ de Arriaga, por la carr. a Tuxtla, 16 $6^{\circ} 19^{\prime} \mathrm{N}$, 9352' O, P. Tenorio L. y J. L. Linares 19785 (MEXU); $7.5 \mathrm{~km}$ al NO de Rizo de Oro sobre camino a Colonia Rodolfo Figueroa, $16^{\circ} 31^{\prime} \mathrm{N}, 9^{\circ} 07^{\prime} \mathrm{O}, T$. Wendt y L. Rico A. 4332 (MEXU).

Especie cercana a Lonchocarpus lineatus Pittier de la Planicie Costera del Golfo de México, que prospera en los estratos arbóreos bajo y mediano de las selvas medianas a altas subcaducifolias a subperennifolias con dominancia de Brosimum, en suelos derivados de rocas calizas, mientras que $L$. isthmensis prospera en la vertiente del Pacifico e Istmo de Tehuantepec, en selvas medianas subcaducifolias y bajas caducifolias. Las diferencias morfológicas entre ambos taxa se contrastan en la diagnosis y la clave dicotómica de las especies de la sección.

En L. isthmensis se presentan dos patrones de distribución (véase los dos grupos separados en el material examinado) el primero representado por poblaciones en la Sierra Madre del Sur y Planicie Costera del Pacífico, habitando en selvas medianas subcaducifolias a bosques mesófilos, en los que la floración se comporta como tardía, y la pelosidad de su fruto tiende a ser más rala. En las poblaciones del Istmo de Tehuantepec y la Depresión Central de Chiapas, la especie prospera en selvas bajas caducifolias y en ecotonías con bosques de Pinus-Quercus, en los que la floración es precoz, o sea que ocurre antes que aparezcan las hojas, y la legumbre cuenta con una pelosidad más densa.

Lonchocarpus latimarginatus M. Sousa, sp. nov. Tipo: México, Veracruz, $10.5 \mathrm{~km}$ al NE de Uxpanapa (Poblado 12) sobre el camino al Poblado 13, 17 $16^{\prime} \mathrm{N}, 94^{\circ} 10^{\prime} \mathrm{O}$, T. Wendt et al. 4046 (holotipo: MEXU!; isotipo: ENCB!). Fig. 4.

Arbor ad $35 \mathrm{~m}$ alta; rami juniores dense ferrugineo-velutini; stipulae 2.5-3 $\mathrm{mm}$ longae; folia (7-)9-11-foliolata, foliolis supra glabrescentibus nitentibusque, infra moderate fusco-flavidis vel ferrugineo-tomentosis, epunctatis. Inflorescentiae (8-)10-18 cm longae, congestiflorae; pedunculi florales (2-)3-4 mm longi, tenues; 
Sousa S.: La sección Lonchocarpus, nuevas especies y subespecie para México y Mesoamérica

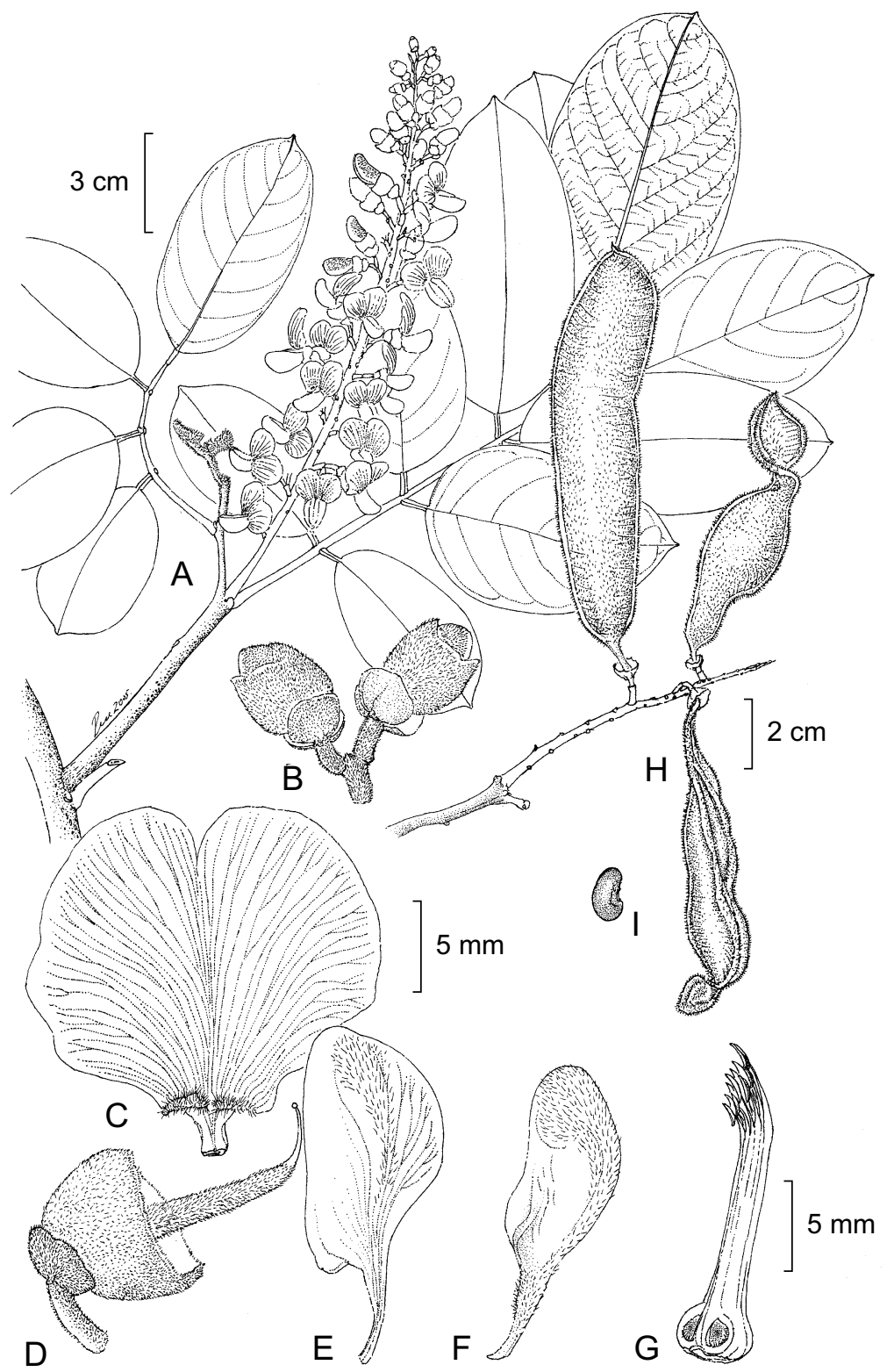

Fig. 4. Lonchocarpus latimarginatus M. Sousa. A. rama con hojas e inflorescencia; B. unidad biflora con pedúnculo floral, pedicelos, bractéolas y botones florales; C. cara abaxial del estandarte; D. cáliz y gineceo; E. ala; F. pétalos de la quilla; G. tubo estaminal; H. infrutescencia y fruto; I. semilla. Rama con inflorescencia y botones florales tomados de $J$. Dorantes et al. 2606 (MEXU); flores y sus partes tomados de T. Wendt et al. 3699 (MO); infrutescencia y semilla tomadas del holotipo: T. Wendt. et al. 4046 (MEXU). 
pedicelli 4-6.5 mm longi; bracteolae 3.5-4 $\mathrm{mm}$ longae, 5-6 $\mathrm{mm}$ latae, oblatae, plus quam trientem calycis tegentes. Flores $16-18 \mathrm{~mm}$ longi, lamina vexilli $18-22 \mathrm{~mm}$ lata; ovarium 10-ovulatum. Legumen indehiscens, 9-12.5 cm longum, ad $2.9 \mathrm{~cm}$ latum, membranaceum vel chartaceum, moderate vel dense fusco-flavidum vel ferrugineo-tomentosum, margine vexillari 11-14 mm crasso, alato. Semina 11-12 mm longa, castanea.

Árboles 15-35 m de alto; brevemente subcaducifolios; corteza interior con fluido resinoso al corte, ramas jóvenes densamente ferrugíneo velutinas, posteriormente glabrescentes. Hojas con estípulas $2.5-3 \mathrm{~mm}$ de largo, ligulares a ovadas, pronto caducas; pecíolo 1.2-3 cm de largo, terete; hojas (7-)9-11-folioladas; folíolos 7.5-11 cm de largo, 3.5-4.2(-5.2) cm de ancho, lanceolados a elípticos o en ocasiones ovados, la base generalmente obtusa, a cortamente cuneada y algo asimétrica, el ápice cortamente acuminado, brillantes y glabros excepto sobre las nervaduras en el haz, moderadamente pardo-amarillento a ferrugíneo tomentulosos en el envés, subcoriáceos, epunteados; nervadura primaria y las secundarias prominentes en el envés, las laterales (6-)8-10 pares. Inflorescencias (8-)10-18 cm de largo, simples, axilares, erectas, frecuentemente paniculáceas, congestifloras, pedunculadas, los pedúnculos muy cortos a casi sésiles, hasta $1.5 \mathrm{~cm}$ de largo, floración precoz a coetánea; pedúnculos florales (2-)3-4 mm de largo, delgados; pedicelos 4-6.5 $\mathrm{mm}$ de largo; bractéolas 3.5-4 mm de largo, 5-6 mm de ancho, oblatas, algo cordatas en la base, opuestas, cercanas, adpresas y cubriendo más de 1/3 del cáliz, persistentes. Flores 16-18 mm de largo; cáliz (5-)6-7 mm de largo, truncado, epunteado, pardoamarillento seríceo; corola rosada, ocasionalmente morada, epunteada, la lámina del estandarte 18-22 $\mathrm{mm}$ de ancho, oblata, densamente canescente serícea adaxialmente, en el centro-base sobre los lóbulos callosos, canescente abaxialmente; ovario 10-ovulado, canescente estrigoso, el estilo curvado. Legumbre 9-12.5 cm de largo, hasta $2.9 \mathrm{~cm}$ de ancho, elíptica a linear oblonga, indehiscente, casi sésil y redondeada en la base, obtusa a rostrada en el ápice, comprimida, las valvas algo abombadas a la altura de las semillas, constricta entre las semillas sobre los márgenes y valvas, membranácea a cartácea, moderada a densamente pardo-amarillenta a ferrugíneo tomentosa, el margen vexilar 11-14 $\mathrm{mm}$ de grueso, alado, cada ala hasta $7 \mathrm{~mm}$ de ancho, el margen carinal aquillado; semillas 1-4, 11-12.2 $\mathrm{mm}$ de largo, 7-8.5 $\mathrm{mm}$ de ancho, ca. $2.8 \mathrm{~mm}$ de grosor, color castaño.

Distribución, hábitat, fenología. Especie endémica a México que habita la Planicie Costera del Golfo de México, en Veracruz, Oaxaca, Tabasco y Chiapas; en 
climas cálidos muy húmedos, donde prosperan las selvas altas perennifolias, en las que esta especie es parte del estrato arbóreo medio y alto; crece en suelos profundos de color café claro de origen calizo; en altitudes bajas de 110-140 m, en Tabasco y Chiapas de 350-500 m. La floración se presenta de mediados de marzo a inicios de abril, la fructificación inicia a principios de mayo, con frutos maduros a mediados del mismo mes.

Etimología. El nombre específico alude al margen vexilar 2-alado del fruto.

Material adicional examinado: MÉXICO: Veracruz: alrededor del Campamento Hermanos Cedillo, municipio Hidalgotitlán, $17^{\circ} 15^{\prime}$ N, 94²40' O, J. Dorantes et al. 2606 (ENCB, MEXU, XAL); km 0-3 camino Plan de Arroyo - Río Alegre, municipio Hidalgotitlán, $17^{\circ} 15^{\prime} \mathrm{N}, 94^{\circ} 40^{\prime} \mathrm{O}$, J. Dorantes et al. 3064 (MEXU, XAL); alrededor del Campamento Cedillo, municipio de Hidalgotitlán, $17^{\circ} 15^{\prime} \mathrm{N}, 94^{\circ} 40^{\prime} \mathrm{O}$, F. Ponce C. 122 (ENCB, IEB, MEXU, XAL); Río Soloxuchil a orilla del Campamento Hermanos Cedillo, municipio Hidalgotitlán, $17^{\circ} 16^{\prime} \mathrm{N}, 94^{\circ} 37^{\prime} \mathrm{O}$, M. Vázquez et al. 127 (MEXU, XAL); $10.5 \mathrm{~km}$ al NE de Uxpanapa (Poblado 12) sobre el camino a Poblado 13, municipio Minatitlán, $17^{\circ} 16^{\prime}$ N, 9410' O, T. Wendt et al. 3699 (ENCB, MEXU, MO), 4101 (ENCB, MEXU).

Oaxaca: DISTRITO JUCHITÁN: carr. Acayucan a Sarabia, poblado Nuevo Ubero, J. I. Calzada 1793 (BM, ENCB, MEXU); a $22 \mathrm{~km}$ NE de Donajii, brecha

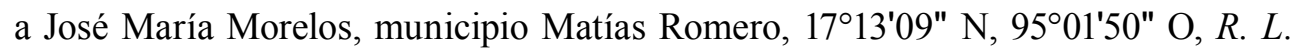
García G. et al. 1118 (MEXU); 7 km O de Esmeralda, en terracería La Laguna - Sarabia $2.6 \mathrm{~km}$ al $\mathrm{S}$ por el camino, $17^{\circ} 07^{\prime} \mathrm{N}, 9^{\circ} 49^{\prime} \mathrm{O}$, T. Wendt et al. 3628 (ENCB, F, MEXU, XAL); Nuevo Progreso, loma al S de la Peñasquera, $17^{\circ} 08^{\prime} 43^{\prime \prime} \mathrm{N}, 95^{\circ} 01^{\prime} 56^{\prime \prime}$ O, A. Nava Zafra 2039 (MEXU).

Tabasco: camino a Candelaria, municipio Huimanguillo, $17^{\circ} 19^{\prime} 43^{\prime \prime} \mathrm{N}$, 9336'78" O. M. A. Guadarrama et al. 6234 (ENCB, MEXU).

Chiapas: $22 \mathrm{~km}$ to $\mathrm{S}$ of Pichucalco on the road to Bochil and Tuxtla Gutiérrez, $17^{\circ} 27^{\prime} \mathrm{N}, 93^{\circ} 05^{\prime} \mathrm{O}$, D. J. Macqueen 562 (MEXU, NY).

Planta sin aparente relación con alguna especie conocida, sin embargo, tiene similitud con el complejo de Lonchocarpus sericeus (Poir.) Kunth ex DC., especialmente con L. tomentosus Tul., árbol propio de Brasil, sobre todo por sus frutos cuyo margen vexilar es bialado, aunque las alas de L. latimarginatus miden hasta $7 \mathrm{~mm}$ de ancho (vs. hasta $3 \mathrm{~mm}$ de ancho). La textura del fruto es membranácea a cartácea (vs. coriácea a subleñosa), la pelosidad ferrugíneo velutina de los órganos vegetati- 
vos así como del fruto (vs. cinérea a pardo-amarillenta); sus bractéolas miden 3.5-4 $\mathrm{mm}$ de largo y 5-6 mm de ancho (vs. 1.5-1.7 mm, por 1.5-2 $\mathrm{mm}$ ) y las flores $16-17$ $\mathrm{mm}$ de largo (vs. 12-14 mm).

Lonchocarpus michoacanicus M. Sousa, sp. nov. Tipo. México, Michoacán: a 4 km al NE de Maruata, camino al Páramo, municipio Aquila, altitud 40 m, 21 octubre 1985, J. C. Soto N., S. Román G. y A. Vidal C. 11237 (holotipo: MEXU; isotipo: MEXU). Fig. 5.

Lonchocarpo hondurensi Benth. similis a quo foliis plerumque 7-foliolatis (vs. 5-foliolatis), inflorescentiis pedunculatis (vs. sessilibus ad fere subsessilibus), bracteolis 0.8-0.9 mm longis (vs. 1-1.2(-2) $\mathrm{mm}$ ); floribus 14-15 mm longis (vs. 10-11 $\mathrm{mm}$ ); lamina vexillari $13-14 \mathrm{~mm}$ lata (vs. 9-11 $\mathrm{mm}$ ) differt.

Árboles 6-15 m de alto; corteza interior con escaso fluido rojizo al corte; ramas jóvenes moderadamente canescente tomentulosas, pronto glabrescentes a glabras. Hojas con estípulas ca. $1.7 \mathrm{~mm}$ de largo, $1.8 \mathrm{~mm}$ de ancho, suborbiculares a oblatas, pronto caducas; pecíolo $2.2-3.2 \mathrm{~cm}$ de largo, con un canalículo adaxial a lo largo del eje foliar; hojas 7-folioladas; folíolos (3.2-)4.5-6.5(-8) cm de largo, (1.5-)2.5-4.5 cm de ancho, elípticos a anchamente elípticos, la base ligeramente cuneada a cuneada, el ápice corto a agudamente acuminado, el folíolo terminal ligeramente más grande que los laterales, algo obovado y más pronunciadamente cuneado en la base, ligeramente brillantes y glabros en el haz, esparcidamente canescente tomentulosos a glabrescentes en el envés, cartáceos a subcoriáceos, epuntedos, la nervadura primaria más prominente que las secundarias, nervaduras laterales 6-7 pares. Inflorescencias $6.5-12 \mathrm{~cm}$ de largo, simples, axilares, erectas, pedunculadas, los pedúnculos $1.5-3 \mathrm{~cm}$ de largo; flores congestas; floración tardía; pedúnculos florales ca. $1.5 \mathrm{~mm}$ de largo, robustos; pedicelos $1.3-2.5 \mathrm{~mm}$ de largo, delgados; bractéolas 0.8-0.9 $\mathrm{mm}$ de largo, 0.9-1 mm de ancho, suborbiculares a ligeramente oblatas, pateniformes, opuestas, adpresas a la base del cáliz. Botones florales elipsoidales. Flores $14-15 \mathrm{~mm}$ de largo, cáliz $2.5-3 \mathrm{~mm}$ de largo, ciatiforme, truncado, epuntedo, moderadamente pardo-amarillento seríceo, con fondo rojizo oscuro; corola morada, epunteda (el ala y la quilla con vesículas alargadas), la lámina del estandarte 13-14 mm de ancho, oblata, densamente canescente serícea adaxialmente, la cara abaxial glabra excepto en la base y en el tercio al medio central, con pelosidad canescente tomentulosa; ovario 9(-10)-ovulado. Legumbre (3-)5-8.5 cm de largo, 1.4-1.8 cm de ancho, oblonga o en ocasiones elíptica, inde- 
Sousa S.: La sección Lonchocarpus, nuevas especies y subespecie para México y Mesoamérica

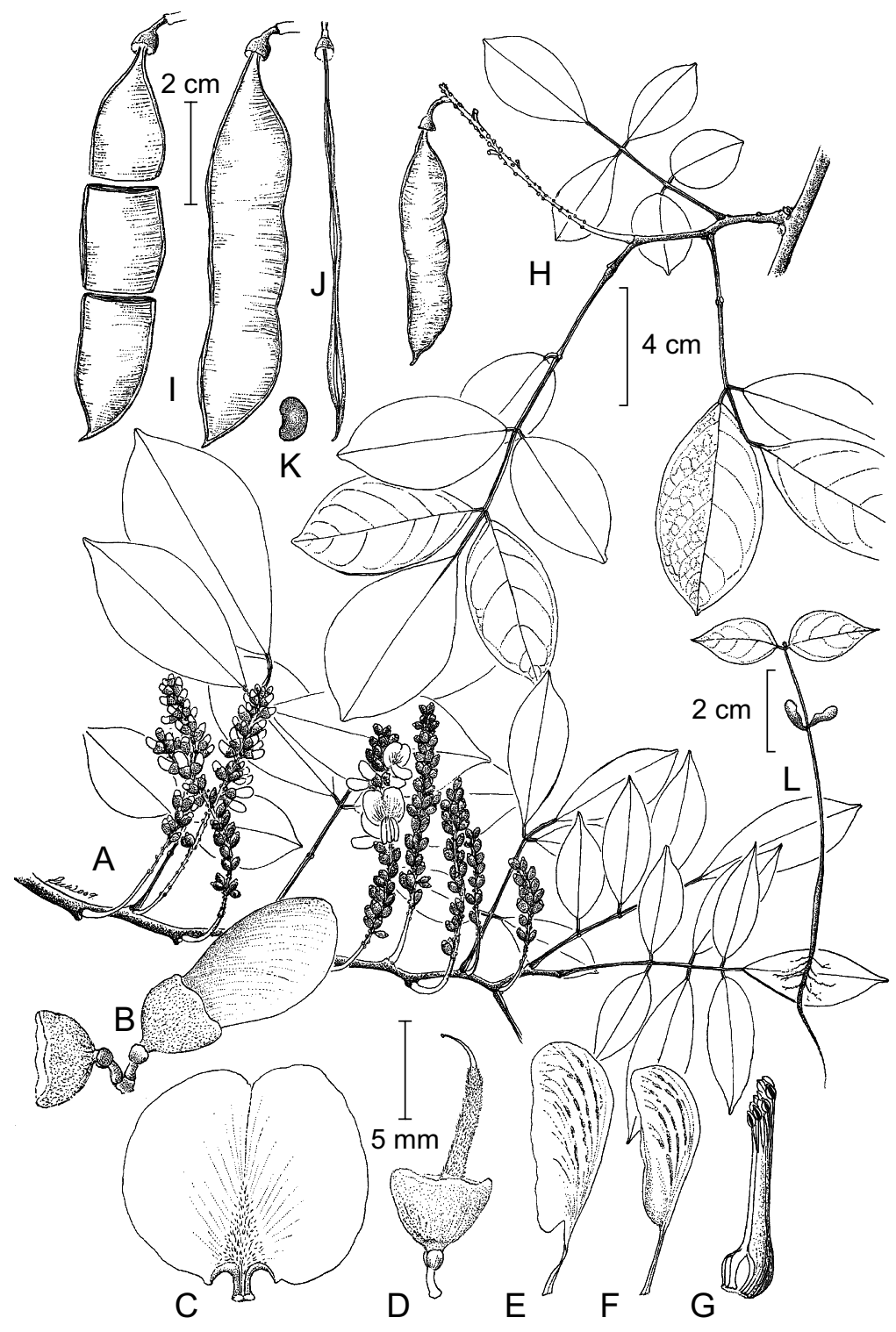

Fig. 5. Lonchocarpus michoacanicus M. Sousa. A. rama con hojas e inflorescencias; B. unidad biflora mostrando pedúnculo floral, pedicelos, bractéolas y botones florales; C. estandarte cara abaxial; D. cáliz y gineceo; E. ala; F. pétalo de la quilla; G. tubo estaminal; H. rama con hojas e inflorescencias; I. frutos mostrando fragmentación; J. margen vexilar del fruto; K. semilla; L. plántula. Rama con inflorescencias, botones florales, flor y sus partes tomadas del holotipo: J.C. Soto 11237 (MEXU); rama con infrutescencia, frutos, semilla y plántula tomados de J.C. Soto 15608 (MEXU). 
hiscente, casi sésil, atenuada en la base, el ápice frecuentemente rostrado, algo constricta entre las semillas, lomentácea fragmentándose en unidades monospermas, coriácea, las valvas nervadas, algo abombadas a la altura de las semillas, esparcidamente canescente tomentosa, el margen vexilar hasta $3 \mathrm{~mm}$ de grueso, enervado, ligeramente sulcado a todo lo largo, el margen carinal ca. $1 \mathrm{~mm}$ de grueso, nervado; semillas 1-5, 8-9.5 mm de largo, 5.5-6 mm de ancho, 2.9-3 mm de grosor, lisas, pardo-amarillentas. Plántulas con los cotiledones epigeos; eófilos opuestos, simples; primera hoja alterna, 3 -foliolada.

Distribución, habitat, fenología: especie endémica al estado de Michoacán, Mexico. En la Planicie Costera del Pacífico, en las vertientes premontanas de la Sierra Madre del Sur, en selvas medianas subcaducifolias, sobre terrenos planos; en altitudes entre 40 y $60 \mathrm{~m}$. La floración de finales de octubre, la fructificación con frutos ya maduros a principios de mayo.

Etimología. El epíteto acentúa que se trata de una especie endémica al estado de Michoacán en México.

Material adicional examinado: México: Michoacán: 2 km al NE de Maruata, camino a Pómaro, municipio Aquila, José Carmen Soto Núñez 15608 (MEXU).

Especie cercana a Lonchocarpus hondurensis Benth., sobre todo por la similitud de sus frutos; en ambas plantas el fruto se segmenta de margen a margen, formando unidades monospermas adaptadas a la dispersión por corrientes de agua; $\sin$ embargo las inflorescencias y flores difieren, véase su comparación en la diagnosis.

Lonchocarpus pedunculatus M. Sousa, sp. nov. Tipo: México. Chiapas, a 14-15 km al S-SE de Altamirano, Río Tzaconeja y carr. Altamirano - Comitán, municipio Altamirano, 10 abril 1995, H. Mejía E. y A. Luna G. 243 (holotipo: MEXU; isotipos: ECOSUR, MEXU). Fig. 6.

Frutices vel arbusculae ca. $3 \mathrm{~m}$ altae; folia 5-7-foliolata; foliola (1.6-)2.3-2.8 cm lata, anguste elliptica vel elliptica, epunctata, apice caudata, supra leviter nitentia, fere glabra, nervis lateralibus 8-14 paribus. Inflorescentiae 2-4 cm longae, erectae, pedunculatae; pedunculi florales 2-2.5 mm longi; bracteolae 0.6-0.8 $\mathrm{mm}$ longae, ca. $1 \mathrm{~mm}$ latae, ovatae vel oblatae, calyce proximae, calycem adpressaeque. Flores 8-9 $\mathrm{mm}$ longi; calyx ca. $2 \mathrm{~mm}$ longus, epunctatus moderate canescenti-sericeus, fundo 
Sousa S.: La sección Lonchocarpus, nuevas especies y subespecie para México y Mesoamérica

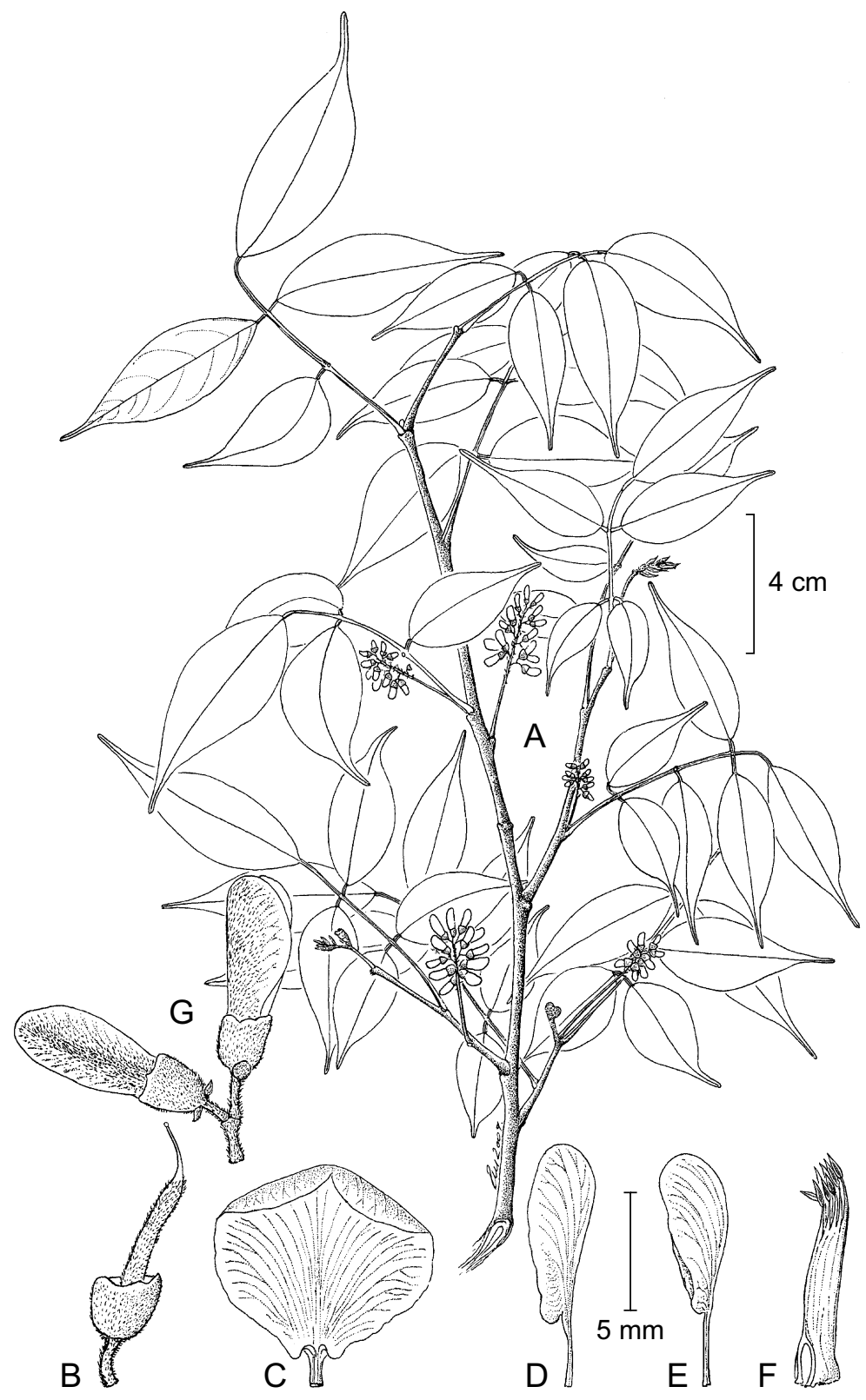

Fig. 6. Lonchocarpus pedunculatus M. Sousa. A. rama con hojas e inflorescencias; B. inicio del desarrollo de un fruto mostrando, pedicelo, cicatriz de una bractéola ya caída, cáliz y gineceo. C. cara abaxial del estandarte; D. ala; E. pétalos de la quilla; F. tubo estaminal; G. unidad biflora, mostrando pedúnculo floral, pedicelos, bractéolas y botones florales. Todos los órganos fueron tomados del holotipo: Mejía y Luna 243 (MEXU). 
manifesto atro-rubescenti; lamina vexillaris ca. $9 \mathrm{~mm}$ lata; ovarium 6-ovulatum. Fructus incognitus.

Arbustos a arbolitos ca. $3 \mathrm{~m}$ de alto; corteza interior sin fluido resinoso rojizo al corte; ramas jóvenes pardo-amarillento seríceas, pronto glabrescentes. Hojas con estípulas ca. $1 \mathrm{~mm}$ de largo, lanceoladas, pronto caducas; pecíolo $2.3-3 \mathrm{~cm}$ de largo, canaliculado adaxialmente; hojas 5-7-folioladas; folíolos 4.5-7.5 cm de largo, (1.6-)2.3-2.8 cm de ancho, angostamente elípticos a elípticos o lanceolado-elípticos, cartáceos, epunteados, concoloros, la base cuneada a ligeramente cuneada, el ápice caudado, el haz ligeramente brillante, casi glabro, excepto el nervio medio pardoamarillento tomentuloso, así como las venas secundarias que llevan pelosidad muy esparcida, el envés ligeramente más peloso; nervaduras primaria y secundarias algo realzadas en el envés, las laterales 8-14 pares. Inflorescencias 2-4 cm de largo, simples, axilares, erectas, congestifloras en el ápice, pedunculadas, el pedúnculo 1.5$2.5 \mathrm{~cm}$ de largo; floración tardía; pedúnculos florales 2-2.5 $\mathrm{mm}$ de largo, delgados; pedicelos 1.5-2.5 mm de largo; bractéolas 0.6-0.8 $\mathrm{mm}$ de largo, ca. $1 \mathrm{~mm}$ de ancho, ovadas a oblatas, cercanas y adpresas al cáliz, opuestas, caducas. Flores $8-9 \mathrm{~mm}$ de largo; cáliz ca. $2 \mathrm{~mm}$ de largo, casi truncado, epunteado, moderadamente canescente seríceo, con un fondo visible rojizo oscuro; corola morada, epunteada, esparcidamente canescente serícea, la lámina del estandarte ca. $9 \mathrm{~mm}$ de ancho, suborbicular a oblata reflexa, cóncava, cara adaxial moderadamente pelosa, sobre todo en las nervaduras y ápice, márgenes glabros, en la base-centro biauricular y bicallosa del lado abaxial, y esparcidamente velutina, la uña ca. $1.5 \mathrm{~mm}$ de largo; ovario 6-ovulado. Legumbre se desconoce.

Distribución, hábitat, fenología. Especie solamente conocida de una recolecta en el estado de Chiapas, México; en la Meseta Central de Chiapas; en vegetación riparia, con encinares circundantes; en altitudes alrededor de los $1240 \mathrm{~m}$. Florece a principios de abril, desconociéndose su período de fructificación.

Etimología. El epíteto aduce al hecho de que su inflorescencia es pedunculada.

Especie característica por sus foliolos largamente caudados que propician la presencia de numerosas (8-14 pares) nervaduras laterales; inflorescencias pedunculadas, erectas con flores de tamaño pequeño (8-9 mm de largo). Al desconocerse sus frutos su relación con otras especies de la sect. Lonchocarpus aún está por definirse. 
Lonchocarpus plicatus M. Sousa, sp. nov. Tipo. México, Veracruz, puente Río Actopan, tramo a la Bocana, municipio Actopan, 27 enero 1992, J. I. Calzada 17552 (holotipo: MEXU; isotipos: ENCB, MEXU, MO). Fig. 7.

Nombre común: palo cal (en Veracruz).

Lonchocarpo yucatanensi Pittier similis a quo foliis 3-foliolatis (vs. 5(-7)-foliolatis); foliolis marginibus undulatis (vs. applanatis), apicibus acuminatis vel longe acuminatis (vs. breviter acuminatis vel obtusis); calyce, bracteolis et pedicellis fusco-flavidis sericeis (vs. canescenti-sericeis); ovario 5-6-ovulato (vs. 7-9-ovulato) differt.

Arbolitos 3-6 m de alto, caducifolios; corteza interior sin fluido resinoso al corte; ramas jóvenes moderada a densamente canescente a cinéreo seríceas, posteriormente glabrescentes a glabras. Hojas con estípulas 0.6-0.8 mm de largo, 0.5-0.7 $\mathrm{mm}$ de ancho, ovadas a triangulares, pronto caducas; pecíolo (1.2-)2.3-3.5 cm de largo, canaliculado; hojas 3-folioladas; folíolos 3.2-8.5(-10) cm de largo, 1.6-2.8(-3.8) $\mathrm{cm}$ de ancho, el folíolo terminal más grande que los laterales, elípticos a lanceolados, algo discoloros, la base ligeramente cuneada a cuneada o algo redondeada, los márgenes ondulados, el ápice acuminado a largamente acuminado, cartáceos, epunteados, opacos, muy esparcidamente canescente seríceos a glabrescentes en el haz, esparcidamente canescentes en el envés, nervadura primaria y secundarias ligeramente realzadas en el envés, nervaduras laterales 7-8 pares. Inflorescencias 4-8.6 cm de largo, simples, axilares, pedunculadas, el pedúnculo 1.5-2.5 $\mathrm{cm}$ de largo, flores espaciadas, floración tardía; pedúnculos florales 0.8-2.1 mm de largo, robustos; pedicelos 1.2-2.4 mm de largo; bractéolas $0.5-0.8 \mathrm{~mm}$ de largo, ovadas, cercanas al cáliz, adpresas a él o patentes. Botones florales elipsoidales. Flores 7.5-8 $\mathrm{mm}$ de largo; cáliz 2-2.2 mm de largo, ciatiforme, casi truncado, epunteado, moderadamente pardo-amarillento seríceo sobre un fondo rojizo oscuro; corola de color violeta o morada, epunteada, esparcidamente canescente serícea; estandarte reflexo, la lámina 7-7.5 mm de ancho, oblata, cóncava, en la porción central moderadamente serícea del lado abaxial, glabra, biauricular y bicallosa adaxialmente; ovario 5-6-ovulado. Legumbre 3-4.5 cm de largo cuando con una a tres semillas, $4.5-5.5 \mathrm{~cm}$ de largo cuando con cinco, 0.9-1.1 cm de ancho, linear-oblonga, indehiscente, membranácea, esparcidamente canescente serícea a glabrescente, ligeramente atenuada en la base, casi sésil, atenuada a obtusa y rostrada en el ápice, lateralmente comprimida, las valvas abombadas a la altura de las semillas, los márgenes vexilar y carinal angos- 


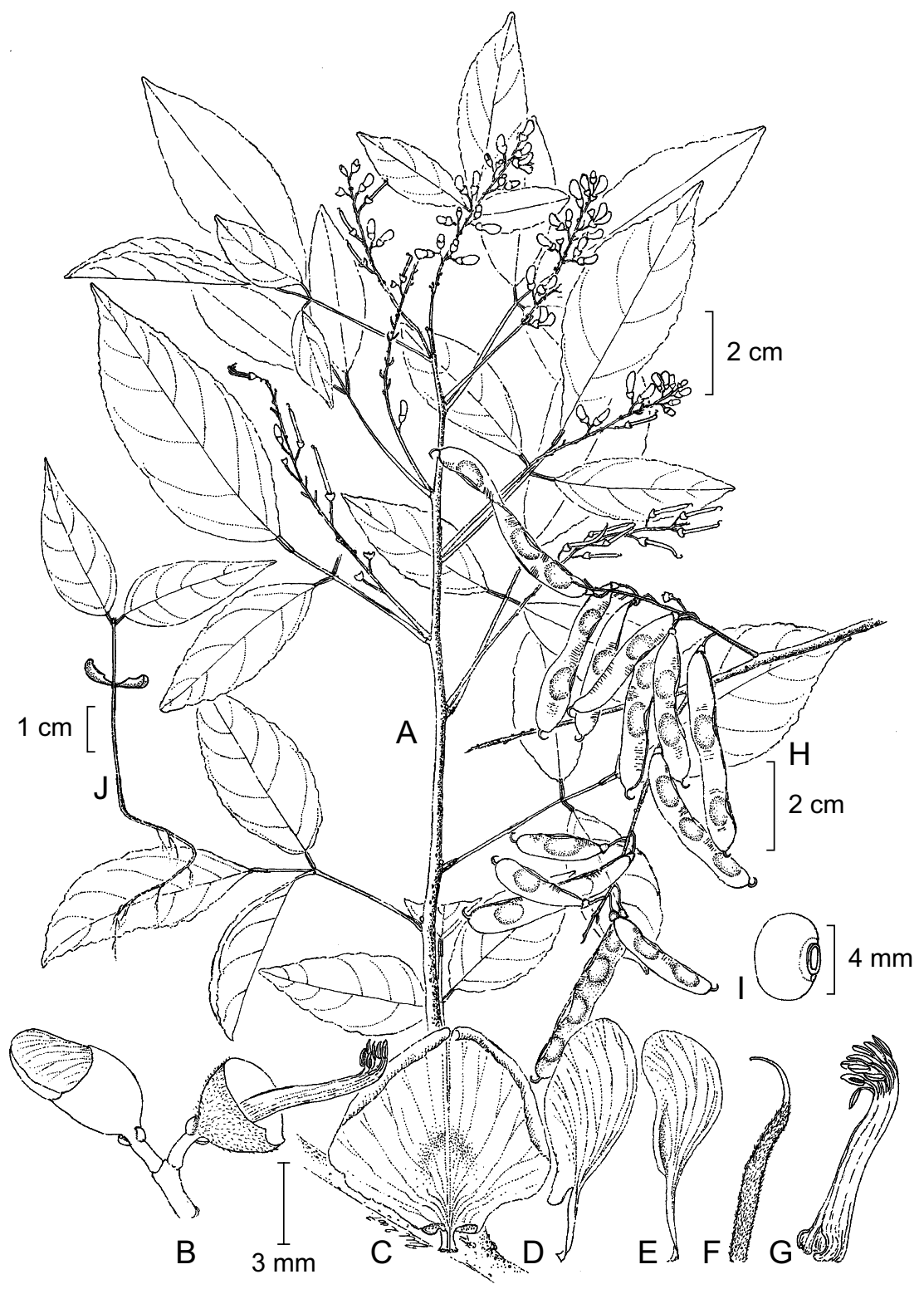

Fig. 7. Lonchocarpus plicatus M. Sousa. A. rama con hojas e inflorescencias; B. unidad biflora mostrando pedúnculo floral, pedicelos, bractéolas, botón floral, cálices; C. cara abaxial del estandarte; D. ala; E. pétalo de la quilla; F. gineceo; G. tubo estaminal; H. infrutescencia y frutos; I. semilla; J. plántula. Rama con inflorescencia tomados de M. Sousa 13280 (MEXU); flor y sus partes tomadas de $J$. Dorantes et al. 5242 (F); rama con infrutescencia y semilla tomadas del holotipo: I. Calzada 17552 (MEXU); plántula tomada de M. Sousa et al. 13373 (MEXU). 
tamente aquillados; semillas 1-5, 6-6.2 $\mathrm{mm}$ de largo, ca. $4.5 \mathrm{~mm}$ de ancho, pardoamarillentas. Plántulas con cotiledones epigeos; eófilos opuestos, simples.

Distribución, hábitat, fenología. Especie sólo conocida del estado de Veracruz, México; en vegetación de selvas bajas caducifolias y selvas medianas subcaducifolias, en los taludes de la vega de ríos y cuerpos lacustres, sobre suelos aluviales, negros y rocosos, así como en depósitos de cenizas volcánicas; en altitudes bajas de 100 a $160 \mathrm{~m}$. La floración es de mediados a finales de noviembre, la fructificación se inicia a finales de enero con frutos maduros a principios de abril.

Etimología. El epíteto específico se refiere al margen ondulado de sus folíolos.

Material adicional examinado: MÉXICO: Veracruz: alrededores Laguna Verde, J. Dorantes et al. 5224 (F, MEXU, NY); Puente Río Actopan, a 4 km E-SE de Actopan, municipio Actopan, M. Sousa S. et al. 13280, 13373 (MEXU).

Especie endémica del área fitogeográfica de la Flora Mesoamericana, tiene parentesco con Lonchocarpus yucatanensis Pittier, difiriendo de ella (véase diagnosis) por sus hojas 3-folioladas, folíolos con márgenes ondulados y su ápice acuminado a largamente acuminado, además por la pelosidad de bractéolas y pedicelos, así como en el menor número de óvulos por ovario. Prospera fundamentalmente sobre suelos cuyo sustrato es de cenizas volcánicas.

Lonchocarpus subsessilifolius M. Sousa, sp. nov. Tipo. Belice, Cayo, Mai Loohout Station and Dawn Trail, 17 March 1967, J. Dwyer, T. Elias y R. Maxwell 197 (holotipo: MEXU; isotipo: MO). Fig. 8.

Frutices vel arbusculae, ramis junioribus dense fusco-flavescenti-tomentosis; folia subsessilia 5-foliolata, petiolo plerumque in pulvinulo proximali reducto, ubi praesenti ad $0.8 \mathrm{~cm}$ longo, canaliculato. Foliola epunctata, supra glabra aliquot nitentia, infra moderate fusco-luteolo-tomentosa. Inflorescentiae simplices, congestiflorae, pedunculis floralibus 1-2 mm longis, robustis, pedicellis 1.5-2.5 mm longis; bracteolae 1.1-1.2 mm longae, lanceolato-oblongae. Flores 10-11 mm longi, lamina vexillaris 10-12 mm lata, suborbicularis vel oblata; ovarium 3-4-ovulatum. Legumina 2.3-4 cm longa, 1.4-1.6 cm lata, membranacea, moderate fusco-luteolo-tomentosa, margine vexillari ca. $1 \mathrm{~mm}$ crasso. 


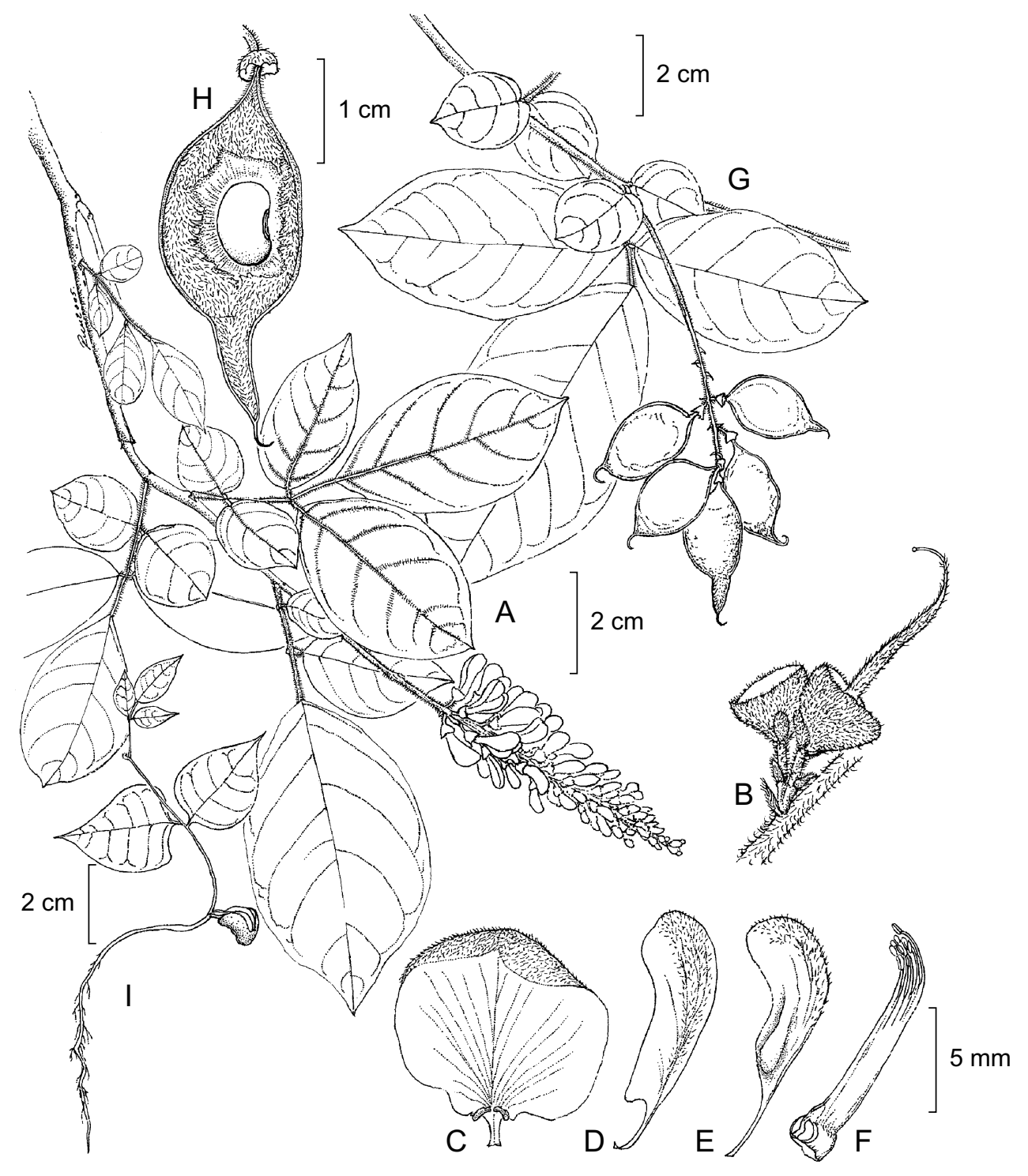

Fig. 8. Lonchocarpus subsessilifolius M. Sousa. A. rama con hojas e inflorescencia; B. unidad biflora mostrando bráctea del pedúnculo floral, pedúnculo floral, brácteas pedicelares, pedicelos, bractéolas, cálices y gineceo; C. cara abaxial del estandarte; D. ala; E. pétalo de la quilla; F. tubo estaminal; rama con hojas e infrutescencia; H. fruto mostrando una semilla; I. plántula. Rama con inflorescencia, flor y sus partes tomados de G. Proctor 29694 (IJ); rama con infrutescencia, fruto y semilla tomados del isotipo: J. Dwyer et al. 197 (MO); plántula tomada de M. Sousa 4185 (MEXU). 
Arbustos a arbolitos 3-6.5 m; corteza interior sin fluido resinoso al corte; ramas jóvenes densamente pardo-amarillento tomentosas, posteriormente en forma esparcida. Hojas con estípulas 1-2 mm de largo, 0.7-1 $\mathrm{mm}$ de ancho, triangulares, pronto caducas; pecíolo generalmente reducido al pulvínulo proximal, cuando presente (en hojas maduras), hasta $0.8 \mathrm{~cm}$ de largo, acanalado; hojas 5-folioladas; folíolo apical mucho más grande que los laterales, (4-)6-7.5 cm de largo, (2.3-)3.7-4.2 cm de ancho, el par distal 4.5-5.5 cm de largo, 2.3-3.2 cm de ancho, el par proximal reflexo, 1-2 cm de largo, 0.8-1.8 $\mathrm{cm}$ de ancho, elípticos, ovados, membranáceos a cartáceos, epunteados, algo discoloros, la base cuneada a en ocasiones redondeada, el ápice acuminado, cortamente acuminado a obtuso, el haz algo brillante, glabro, el envés moderadamente pardo-amarillento tomentoso, más densamente sobre las nervaduras; nervadura primaria y secundarias algo realzadas en el envés, las laterales 5-6 pares. Inflorescencias 5.5-10 cm de largo, simples, axilares, erectas, congestifloras, pedunculadas, los pedúnculos $1.7-2.5 \mathrm{~cm}$ de largo; floración tardía; pedúnculos florales 1-2 mm de largo, robustos; pedicelos 1.5-2.5 mm de largo; bractéolas 1.1-1.2 $\mathrm{mm}$ de largo, 0.6-0.8 $\mathrm{mm}$ de ancho, lanceoladooblongas, adpresas al cáliz a patentes, opuestas, caducas. Flores 10-11 mm de largo; cáliz 3-4 mm de largo, casi truncado, epunteado, moderadamente pardo-amarillento seríceo sobre un fondo de color guinda oscuro; corola de color púrpura, epunteada, moderadamente canescente serícea; estandarte reflexo, cóncavo, la lámina 10-12 mm de ancho, suborbicular a oblata, serícea principalmente en el ápice del lado adaxial; ovario 3-4-ovulado. Legumbre 2.3-2.5 cm de largo cuando con una semilla, ca. $4 \mathrm{~cm}$ de largo cuando con dos semillas, 1.4-1.6 cm de ancho, elíptica a oblonga, indehiscente, aplanada, membranácea, moderadamente pardo-amarillento tomentosa, cortamente estipitada en la base, redondeada y rostrada en el ápice, ligeramente constricta entre las semillas sobre los márgenes, el margen vexilar ca. $1 \mathrm{~mm}$ de grueso, aplanado, el margen carinal angostamente aquillado; semillas (inmaduras) 1-2. Plántulas con cotiledones epigeos; eófilos opuestos, simples, primeras hojas alternas 3 -folioladas con el pecíolo bien desarrollado.

Distribución, hábitat, fenología. Especie endémica de las Montañas Mayas de Belice, sobre cerros cársticos con selvas subperennifolias a subcaducifolias con Brosimum alicastrum y Protium copal, como parte del estrato arbóreo bajo. En altitudes entre 460-550 m. La floración se presenta a principios de diciembre; la fructificación a mediados de marzo. 
Etimología. El nombre de la especie hace énfasis en sus características hojas subsésiles.

Material adicional examinado: BELICE: Cayo: Los Altos Hill, Augustine, G. R. Proctor 29650 (BM, IJ, LL), 29694 (IJ); Cuevas de Río Frío, 1 km al O de Augustine, M. Sousa S. 4185 (MEXU).

Especie única en el género Lonchocarpus por contar con hojas casi sésiles; conocida solamente de las Montañas Mayas de Belice, sobre suelos de origen calizo.

Lonchocarpus wendtii M. Sousa, sp. nov. Tipo: México, Veracruz, $1 \mathrm{~km}$ al E de La

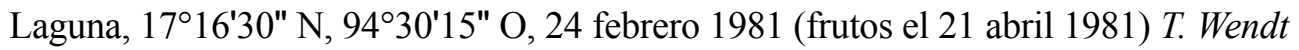
A. Villalobos C. e I. Navarrete 2925 (holotipo: MEXU; isotipos: ENCB, F, IBUG, INEGI, NY, XAL). Fig. 9.

Nombres comunes: marinero (Oaxaca), rosa morada (Veracruz).

Arbor ad $35 \mathrm{~m}$ alta, rami juniores moderate canescenti-sericei; folia 3-5(-7)foliolata, supra glabra, foliolis apice plerumque caudato; inflorescentiae fere sessiles; pedunculi florales (0.6-)1.5-2.5 mm longi; pedicelli 1.5-3 mm longi; bracteolae $1.3 \mathrm{~mm}$ longae, ovatae vel late oblongae, calycem adpressae; flores 9-12 $\mathrm{mm}$ longi; calyx corollaque epunctata; ovarium 7-10 ovulatum. Legumen 4.5-7.5 longum, 0.7-1 $\mathrm{cm}$ latum, lineri-oblongum, membranaceum, glabrum, fere sessile, apice rotundatum vel rostratum, lateraliter compressum, valvis in quoque seminis loco distentorotundatis, margine vexillari carinato vel leviter dilatato ad $3 \mathrm{~mm}$ crasso; semina 3-7, 7.6-7.8 mm longa, brunneo-flavescentia. Plantulae cotyledonibus epigaeis; eophylli oppositi, simplices.

Árboles 10-25(-35) m de alto; corteza interior con o sin fluido resinoso rojizo al corte; ramas jóvenes moderadamente canescentes o pardo-amarillento seríceas, pronto glabras. Hojas con estípulas 0.9-1.2 $\mathrm{mm}$ de largo, 0.8-0.9 $\mathrm{mm}$ de ancho, ovadas a lanceoladas, pronto caducas; pecíolo 1.5-2.9 cm de largo, acanalado; hojas 3-5(-7)folioladas; folíolos (2.7-)4-8(-12) cm de largo, (1.7-)2.2-4(-5.2) cm de ancho, angostamente elípticos a lanceolado-elípticos, en ocasiones elípticos, cartáceos, epunteados, concoloros a ligeramente discoloros, la base cuneada o en ocasiones redondeada, el ápice acuminado, largamente acuminado a caudado, cartáceos, epunteados, el haz 
Sousa S.: La sección Lonchocarpus, nuevas especies y subespecie para México y Mesoamérica

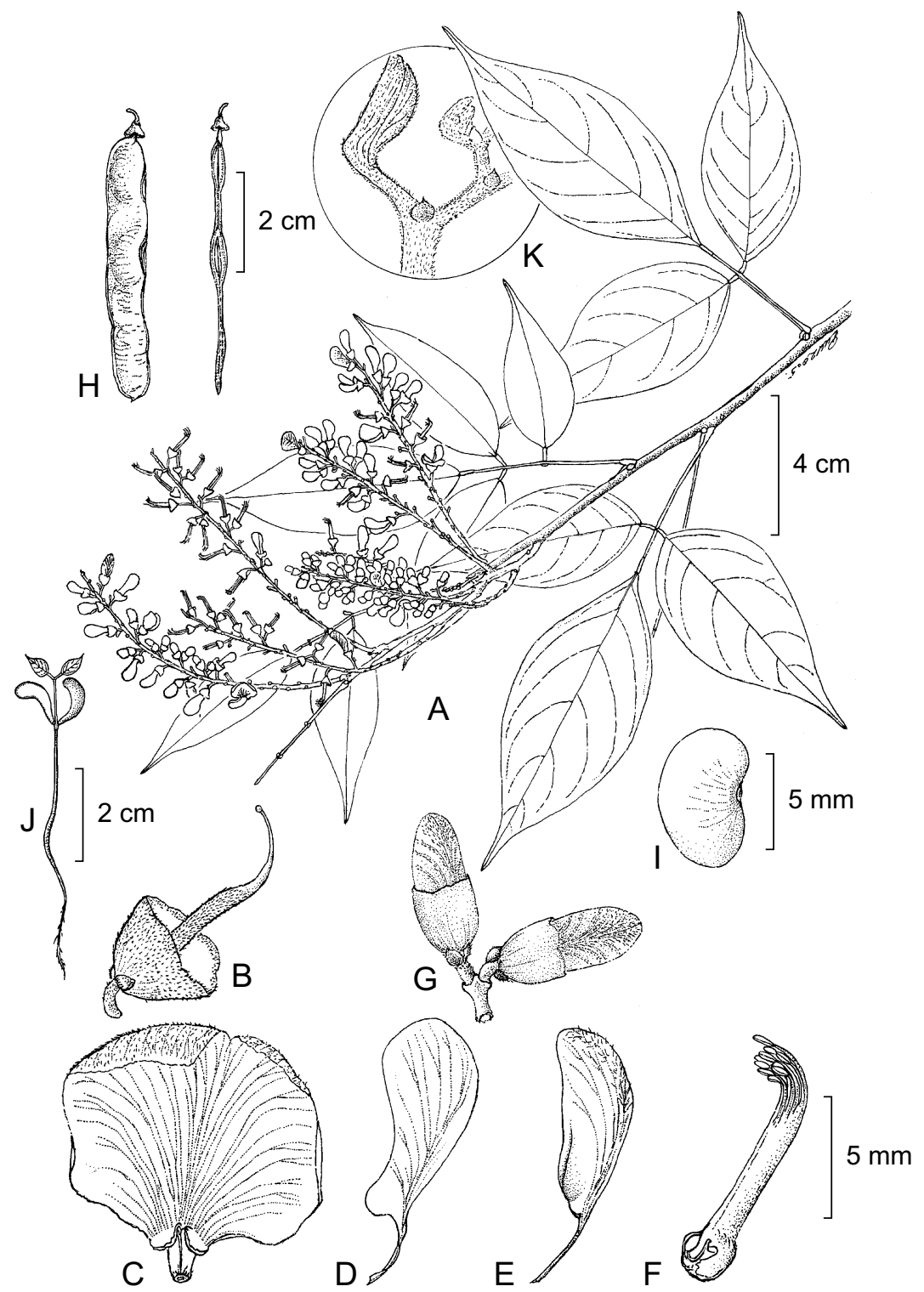

Fig. 9. Lonchocarpus wendtii M. Sousa. A. rama con hojas e inflorescencias; B. cáliz y gineceo; C. cara abaxial del estandarte; D. ala; E. pétalo de la quilla; F. tubo estaminal; G. unidad biflora mostrando pedúnculo floral, pedicelos, bractéolas y botones florales; $\mathrm{H}$. frutos mostrando cara valvar y margen vexilar; I. semilla; J. plántula; K. yema mostrando estípula. Rama con inflorescencias, fruto y semilla tomados de T. Wendt 2925 (MEXU); unidad biflora, flor y sus partes tomadas de P. Tenorio et al. 5578 (MEXU); plántula y yema vegetativa tomados de M. Sousa 13098 (MEXU). 
algo brillante, glabro, el envés glabrescente, esparcidamente canescente piloso sobre la nervadura media a ligeramente pardo-amarillento seríceo sobre las nervaduras; nervadura primaria y secundarias algo realzadas en el envés, las laterales 6-9 pares. Inflorescencias $1.5-8 \mathrm{~cm}$ de largo, generalmente simples, axilares, a paniculáceas, erectas, congestifloras, cortamente pedunculadas, el pedúnculo $0.5-1 \mathrm{~cm}$ de largo, a casi sésiles; floración precoz, coetánea o en ocasiones tardía; pedúnculos florales (0.6-)1.5-2.5 mm de largo, robustos a delgados; pedicelos 1.5-3 mm de largo; bractéolas 1-3 mm de largo, ovadas, suborbiculares a anchamente oblongas, adpresas al cáliz, opuestas, caducas. Botones florales elipsoidales. Flores 9-12 mm de largo; cáliz 2.3-3.5 mm de largo, casi truncado, epunteado, pardo-amarillento seríceo sobre un fondo pardo a negruzco; corola de color lila, rosado-lavanda o morada, epunteada, esparcidamente canescente serícea a casi glabra, el estandarte sólo moderadamente, sobre todo en las nervaduras del lado adaxial, reflexo, cóncavo, la lámina (9-)11-11.5 $\mathrm{mm}$ de ancho, suborbicular a oblata, serícea sobre las nervaduras adaxialmente, en la base-centro biauricular y bicallosa con pelosidad canescente escasa prolongándose a la uña abaxialmente; ovario 7-10-ovulado. Legumbre 4.5-7.5 cm de largo, 0.8-1 cm de ancho, linear-oblonga, indehiscente, membranácea, glabra, pardoamarillenta, ligeramente atenuada en la base, casi sésil, redondeada a rostrada en el ápice, lateralmente comprimida, las valvas abombadas a la altura de las semillas, el margen vexilar con muescas a la altura de las semillas, ligeramente ensanchado o sin ensanchar, hasta $3 \mathrm{~mm}$ de grosor, 3 -nervado, el margen carinal angostamente aquillado; semillas (1-)3-7, 7.6-10 mm de largo, 4.8-5 mm de ancho, pardo-amarillentas. Plántulas con los cotiledones epígeos; eófilos opuestos, simples.

Distribución, hábitat y fenología: Especie sólo conocida de la Planicie Costera del Golfo de México de Veracruz a Guatemala, en climas cálido-húmedos. Habita en selvas medianas a altas subperennifolias a perennifolias con Brosimun alicastrum, Dialium, Bernoullia, Ficus y Robinsonella, en los estratos arbóreos medio a superior; sobre suelos calizos de color café claro amarillo y rojo lateríticos. En altitudes bajas 70-180 m. La floración es de inicios de diciembre a mediados de abril; la fructificación se presenta de finales de abril a inicios de mayo.

Etimología. Se dedica esta especie al botánico dendrólogo norteamericano Thomas Leighton Wendt (1950-), quien trabajó en el Colegio de Postgraduados en México sobre los árboles tropicales de las selvas húmedas de México; tema que ha continuado, colectando particularmente las especies del dosel de la selva, lo que ha redituado en numerosos hallazgos nuevos para la ciencia. 
Material adicional examinado: MÉXICO: Veracruz: cerca del camino a Plan de Arroyos-Álvaro Obregón, municipio Hidalgotitlán, $17^{\circ} 15^{\prime} \mathrm{N}, 94^{\circ} 40^{\prime} \mathrm{O}, \mathrm{J}$. Dorantes et al. 2900 (BM, ENCB, MEXU, MO); Campamento Hermanos Cedillo a 4 km S, en el camino a Arroyo Seco, municipio Hidalgotitlán, B. Ortiz y Martiniano 22 (ENCB, MEXU); Río Soloxochil al SO del Campamento Hermanos Cedillo, municipio Hidalgotitlán, F. Ponce C. 255 (F, MEXU, XAL); a 7 km del Campamento Hermanos Cedillo, hacia el SO Río Alegre, municipio Hidalgotitlán $17^{\circ} 15^{\prime} 30^{\prime \prime} \mathrm{N}$, 9441'30" O, P. E. Valdivia PV-20 (MEXU); $8 \mathrm{~km}$ al S de Hermanos Cedillo, rumbo a Río Alegre, M. Vázquez et al. v-126 (MEXU); Río Soloxochil, entre Hermanos Cedillo y La Escuadra, municipio Hidalgotitlán, M. Vázquez et al. 363 (MEXU, MO); $2 \mathrm{~km}$ al $\mathrm{N}$ del Poblado 2, municipio Jesús Carranza, T. Wendt y G. Schatz 4398 (CHAPA, MEXU), Wendt y Hernández 5284 (CHAPA, MEXU).

Oaxaca: DISTRITO TUXTEPEC: lado E de Isla Isabel María, Presa Temazcal, municipio San Miguel Soyaltepec, L. Cortés et al. 822 (MEXU); Isla Isabel María, orilla E, en la presa Miguel Alemán, al O de Temazcal, municipio San Miguel Soyaltepec, M. Sousa S. et al. 13098 (MEXU).

Tabasco: El Azufre, $16 \mathrm{~km}$ al E de Teapa, municipio Teapa, $17^{\circ} 35^{\prime} \mathrm{N}, 92^{\circ} 50^{\prime}$ O, P. Tenorio L. et al. 5598 (MEXU).

GUATEMALA: Petén: Los Arcos, bordering Río San Pedro, E of km 165 on Cárdenas Road, E. Contreras 9390 (F, LL, MEXU, MO, NY).

Chiquimula: sin localidad, $S$. Watson 54 (GH).

Especie muy característica por sus hojas con folíolos glabros y de ápices con frecuencia largamente acuminados a caudados y su hábitat en los estratos medios a altos de selvas medianas subperennifolias a altas perennifolias.

Lonchocarpus wendtii pertenece a un grupo de especies relacionadas, $L$. yucatanensis y L. plicatus, las que cuentan con frutos pequeños, ((2-)3-4.5 cm de largo), y angostos (0.7-1.1 cm de ancho), linear-oblongos y con los márgenes rectos. Este grupo es endémico de la Planicie Costera del Golfo de México, en donde sus especies muestran una distribución alopátrica.

Clave de las especies mexicanas y mesoamericanas de Lonchocarpus sect. Lonchocarpus

1 Bractéolas cubriendo a la base del cáliz en un 1/4 o más de ella, no patentes.

2 Legumbres con el margen vexilar aquillado (complejo L. cruentus).

3 Flores 10.5-12 $\mathrm{mm}$ de largo L. cruentus Lundell 
3 Flores 13.5-16 mm de largo.

4 Folíolos frecuentemente los proximales, tienden a ser alternos sobre el raquis foliar; estípulas ca. $2 \mathrm{~mm}$ de largo; hojas 11-13(-17)-folioladas; flores esparcidas; lámina del estandarte ca. $1.3 \mathrm{~mm}$ de ancho; legumbres densamente pelosas L. alternifoliolatus $\mathrm{M}$. Sousa

4 Folíolos generalmente opuestos sobre el raquis foliar; estipulas 3-4 $\mathrm{mm}$ de largo; hojas (13-)15-19(-21)-folioladas; flores densamente agrupadas; lámina del estandarte $17-18 \mathrm{~mm}$ de ancho; legumbres moderada a esparcidamente pelosas a glabrescentes

L. septentrionalis $\mathrm{M}$. Sousa

2 Legumbres sin margen vexilar aquillado.

5 Pelosidad vegetativa densamente ferrugínea; pedicelos 4-6.5 mm de largo; legumbres con el margen vexilar con 2-crestas laterales aliformes

L. latimarginatus $\mathrm{M}$. Sousa

5 Pelosidad vegetativa moderadamente pardo-amarillenta, pronto glabrescente; pedicelos 1-3.5 mm de largo; legumbres con el margen vexilar sin crestas aliformes.

6 Inflorescencias pedunculadas; bractéolas 1.2-2 mm de largo; legumbres leñosas, fuertemente abombadas, con particiones lomentáceas, el margen vexilar 7-9(-14) $\mathrm{mm}$ de grueso, con 3 crestas leñosas, las laterales frecuentemente abombadas, la central más aguda y con dos fisuras entre ellas a todo lo largo ............................. L. palmeri Rose

6 Inflorescencias sésiles a casi sésiles; bractéolas 2-5 mm de largo; legumbres membranáceas a cartáceas, aplanadas, sin particiones lomentáceas, el margen vexilar 2-3 $\mathrm{mm}$ de grueso, con nervaduras a todo lo largo y sin fisuras L. salvadorensis Pittier

1 Bractéolas cubriendo la base del cáliz en menos de 1/4 de ella, en ocasiones distalmente patentes.

7 Hojas subsésiles, el pecíolo generalmente sólo representado por un pulvínulo, en ocasiones el pecíolo hasta $8 \mathrm{~mm}$ de largo .... L. subsessilifolius M. Sousa 7 Hojas con el pecíolo bien desarrollado.

8 Hojas mayoritariamente 3-5-folioladas, en ocasiones 7-folioladas, pero no más, en L.chiangii y L. oliganthus tan frecuentemente 5 como 7-folioladas.

9 Folíolos obtusos a cortamente acuminados.

10 Corteza interior con abundante fluido resinoso rojizo al corte; frutos coriáceos, 1.5-2 cm de ancho; bractéolas 1-1.2(-2) mm de largo; flores $10-11 \mathrm{~mm}$ de largo L. hondurensis Benth. 
10 Corteza interior sin aparente fluido resinoso al corte; frutos membranáceos a cartáceos, 0.7-0.9 cm de ancho; bractéolas 0.7$0.8 \mathrm{~mm}$ de largo; flores $8-9(-10) \mathrm{mm}$ de largo

L. yucatanensis Pittier

9 Folíolos acuminados, largamente acuminados a caudados.

11 Frutos (desconocidos en L. pedunculatus) $1.3-2.5 \mathrm{~cm}$ de ancho.

12 Folíolos hasta $9.5 \mathrm{~cm}$ de largo y hasta $5.5 \mathrm{~cm}$ de ancho.

13 Flores 14-15 mm de largo; lámina del estandarte 13-14 mm de ancho, oblata; ovario 9-10-ovulado

L. michoacanicus M. Sousa

13 Flores 5.7-9 mm de largo; lámina del estandarte 6-9 mm de ancho, oblonga a suborbicular; ovario 5-6-ovulado.

14 Árboles (4-)6-10(-15) $\mathrm{m}$ de alto; foliolos con nervaduras laterales de 4-8 pares; inflorescencias hasta $12 \mathrm{~cm}$ de largo, péndulas; pedúnculos florales $0.8-1.5 \mathrm{~mm}$ de largo; lámina del estandarte 6-6.5 mm de ancho

L. chiangii M. Sousa

14 Arbustos a arbolitos ca. $3 \mathrm{~m}$ de alto; foliolos con nervaduras laterales de 8-14 pares; inflorescencias hasta $4 \mathrm{~cm}$ de largo, erectas, pedúnculos florales $2-2.5 \mathrm{~mm}$ de largo; lámina del estandarte ca. $9 \mathrm{~mm}$ de ancho

L. pedunculatus M. Sousa

12 Folíolos hasta $11.5-17 \mathrm{~cm}$ de largo y hasta $7-8.5 \mathrm{~cm}$ de ancho.

15 Ramas jóvenes densamente ferrugíneo tomentosas, posteriormente en forma moderada; inflorescencias subsésiles; flores congestas L. lineatus Pittier

15 Ramas jóvenes moderadamente canescente seríceas, posteriormente glabras; inflorescencias pedunculadas, el pedúnculo $1.5-3 \mathrm{~cm}$ de largo; flores espaciadas

L. oliganthus F. J. Hermann

11 Frutos (desconocidos en L. pedunculatus) $0.7-1.1 \mathrm{~cm}$ de ancho.

16 Inflorescencias casi sésiles; árboles hasta $35 \mathrm{~m}$ de alto; flores 9-12 $\mathrm{mm}$ de largo L. wendtii M. Sousa

16 Inflorescencias pedunculadas; arbustos a arbolitos hasta $6 \mathrm{~m}$ de alto; flores 7.5-9 $\mathrm{mm}$ de largo. 
17 Hojas 3-folioladas, los márgenes foliolares ondulados; nervaduras laterales 7-8 pares; inflorescencias $4-8.6 \mathrm{~cm}$ de largo, flores esparcidas; pedúnculos florales 0.8-2.1 mm de largo, robustos ................................. L. plicatus M. Sousa

17 Hojas 7-folioladas, los márgenes foliolares aplanados; nervaduras laterales 8-14 pares; inflorescencias 2-4 cm de largo, flores densamente agrupadas; pedúnculos florales 2-2.5 mm de largo, delgados ..... L. pedunculatus M. Sousa

8 Hojas mayoritariamente con 7 o más folíolos, rara vez con menos.

18 Bractéolas 0.8-1 mm de largo, oblongas a lanceoladas, cáliz cortamente dentado; frutos 0.9-1.4 cm de ancho, membranáceos, tomentulosos a velutinos L. isthmensis M. Sousa

18 Bractéolas 1.2-1.8 mm de largo, suborbiculares a oblatas; cáliz truncado; frutos (1.5-)1.7-2.1(-2.5) cm de ancho, cartáceos, coriáceos a subleñosos, seríceos a glabrescentes.

19 Bractéolas algo reflexas, adpresas al cáliz en su base, patentes y aquilladas en su ápice; legumbres con el margen vexilar (3-)4.5$5.5 \mathrm{~mm}$ de grueso L. macrophyllus Kunth

19 Bractéolas adpresas en toda su longitud; legumbres con el margen vexilar 2-3.3 $\mathrm{mm}$ de grueso.

20 Folíolos elípticos a angostamente elípticos, la base largamente cuneada, el ápice acuminado a largamente acuminado; ovario 9-10-ovulado; legumbres $2-2.1 \mathrm{~cm}$ de ancho, las valvas con nervaduras escasas e imperceptibles

L. brenesii M. Sousa subsp. brenesii

20 Folíolos elípticos a anchamente elípticos, la base brevemente cuneada, el ápice cortamente acuminado a obtuso; ovario 6-9ovulado; legumbres $1.5-1.8 \mathrm{~cm}$ de ancho, las valvas con las nervaduras numerosas y realzadas

L. brenesii M. Sousa subsp. vulcanicola M. Sousa

\section{AGRADECIMIENTOS}

A Fernando Chiang C. por su asesoría en un problema nomenclatural y por la traducción de las diagnosis al latín con la contribución de Omar González Zorzano en el latín. A Gloria Andrade M. por su continuo apoyo en la organización del texto 
y de la información. A Alejandra Zaldívar por la incorporación de las descripciones para la Flora Mesoamericana. A Ramiro Cruz por sus magníficas ilustraciones botánicas. Por facilitar, en visitas o préstamos, el material de estudio, a los curadores de los siguientes herbarios: BM, CHAPA, CR, DS, EAP, ENCB, F, GH, IBUG, IEB, IJ, INEGI, LL, MEXU, MICH, MO, NY, US, XAL quienes hicieron posible su consulta.

\section{LITERATURA CITADA}

Sousa S., M. 2005. Las especies del género Lonchocarpus (Leguminosae, Papilionoideae: Millettieae) para Bolivia. Novon 15: 590-598.

Sousa S., M. 2009. Standleyi una nueva sección del género Lonchocarpus (Leguminosae), nuevas especies y subespecies para Mesoamérica y Sudamérica. Acta Bot. Mex. 86: 39-69.

Sousa S., M. 2010. Revisión del complejo de Lonchocarpus cruentus (Leguminosae: Papilionoideae: Millettieae) con la descripción de cinco especies nuevas. Brittonia (en prensa). 